\title{
AN INFORMATION-BASED TRADE OFF BETWEEN FOREIGN DIRECT INVESTMENT AND FOREIGN PORTFOLIO INVESTMENT: VOLATILITY, TRANSPARENCY, AND WELFARE
} Itay Goldstein Assaf Razin

Working Paper 9426

http://www.nber.org/papers/w9426

\section{NATIONAL BUREAU OF ECONOMIC RESEARCH 1050 Massachusetts Avenue Cambridge, MA 02138}

December 2002

We thank Patrick Bolton, Alexander Guembel, Oved Yosha, seminar participants in Cornell University, and participants in the FDI conference (Tel Aviv, May 2002), the LACEA annual meeting (Madrid, October 2002), and the fall meeting of the NBER IFM research group (Camberidge, October 2002) for helpful comments and discussions. All remaining errors are ours. The views expressed herein are those of the authors and not necessarily those of the National Bureau of Economic Research.

(C) 2002 by Itay Goldstein and Assaf Razin. All rights reserved. Short sections of text not to exceed two paragraphs, may be quoted without explicit permission provided that full credit including, (C) notice, is given to the source. 
An Information-Based Trade Off Between Foreign Direct Investment and

Foreign Portfolio Investment: Volatility, Transparency, and Welfare

Itay Goldstein and Assaf Razin

NBER Working Paper No. 9426

December 2002

JEL No. F0, F2, F3, G0

\begin{abstract}
$\underline{\text { ABSTRACT }}$
The paper develops a model of foreign direct investments (FDI) and foreign portfolio investments. FDI is characterized by hands-on management style which enables the owner to obtain relatively refined information about the productivity of the firm. This superiority, relative to portfolio investments, comes with a cost: A firm owned by the relatively well-informed FDI investor has a low resale price because of a "lemons" type asymmetric information between the owner and potential buyers. Consequently, investors, who have a higher (lower) probability of getting a liquidity shock that forces them to sell early, will invest in portfolio (direct) investments. This result can explain the greater volatility of portfolio investments relative to direct investments. Motivated by empirical evidence, we show that this pattern may be weaker in developed economies that have higher levels of transparency in the capital market and better corporate governance. We also study welfare implications of the model.
\end{abstract}

Itay Goldstein

Fuqua School of Business

Duke University

Box 90120

Durham, NC 27708

itayg@duke.edu

\author{
Assaf Razin \\ Eitan Berglas School of Economics \\ Tel Aviv University \\ and \\ Department of Economics \\ Cornell University \\ Uris Building Room 402 \\ Ithaca, NY 14853 \\ and NBER \\ ar256@cornell.edu
}




\section{Introduction}

Foreign direct investment, FDI, has proven to be resilient during financial crises. For example, FDI in East Asian countries was remarkably stable during the global financial crises of 1997-98. In sharp contrast, other forms of private capital flows - portfolio equity and debt flows - were subject to large reversals during the same period (as documented by Lipsey (2001)). The resilience of FDI during financial crises was also evident during the Mexican crisis of 1994-95 and the Latin American debt crisis of the 1980s. As a result, FDI inflows into developing countries are often viewed as stable "cold" money, which are generated by long term considerations of the foreign investors. In contrast, foreign portfolio investments, FPI, are often deemed as unstable "hot" money, which are triggered by short term considerations of the foreign investors.

A similar conclusion follows the analysis of UNCTAD recent data on FDI net inflows. ${ }^{1}$ This data shows that total net inflows of FDI into developing countries were $\$ 187$ billions in $1997, \$ 188$ billions in 1998, $\$ 222$ billions in 1999, and $\$ 240$ billions in 2000 (UNCTAD (2001)), while at the same time net inflows of portfolio investments were much more volatile (see, for example, World Bank (2002)). Using World Bank data on 111 countries, Albuquerque (2002) shows that 89\% of the countries in his sample have lower coefficient of variation of net FDI inflows than that of other net inflows. ${ }^{2}$ Interestingly, Lipsey (1999) shows that the ratio of the volatility of net FDI inflows to the volatility of other net long term inflows is smaller in developing countries than in developed countries: The ratio of FDI's volatility to other long-term flows' volatility is 0.59 in Latin America, 0.74 in South East Asia, 0.86 in Europe, and 0.88 in the US. Thus, the differences in volatilities between net FDI inflows and other types of net inflows are smaller in developed economies. ${ }^{3}$

In this paper, we try to explain why FDI inflows are stable, whereas FPI inflows are volatile

\footnotetext{
${ }^{1}$ Net inflows account for net investments made by foreign investors (that is, new investments by foreign investors minus withdrawals of old investments by foreign investors).

${ }^{2}$ See also Bachetta and van Wincop (2000).

${ }^{3}$ The literature also has plenty of other sources of related evidence: Frankel and Rose (1996) show that the size of FDI flows reduces the probability of currency crises. Chuhan, Perez-Quiros and Popper (1996) show that FDI flows are less sensitive to shocks in other countries and to shocks in other types of investments. Sarno and Taylor (1999) show that FDI flows are more persistent than other flows. Claessens, Dooley, and Warner (1995) provide the only source of mixed evidence. However, they study a smaller sample of countries, which predates the recent international crises.
} 
and tend to be withdrawn during liquidity crises. ${ }^{4}$ We also try to explain why the differences in volatilities between FDI and FPI are smaller in developed economies than in developing economies. We do that by endogenizing the choice of foreign investors between FDI and FPI in a model of an information-based trade off between the two forms of investment. We believe that our model sheds new light on the determinants of the composition of international capital flows, and generates interesting empirical predictions and policy implications.

The model highlights a key difference between the two types of investment: FDI investors, who take both ownership and control positions in the domestic firms, are in effect the managers of the firms under their control; whereas portfolio investors, who gain ownership without control of domestic firms, must delegate decisions to managers, but limit their freedom to make decisions because the latter's agenda may not be always consistent with that of the owners. Consequently, due to an agency problem between managers and owners, portfolio investment projects are managed less efficiently than direct investment projects. To be more specific, direct investors, who act effectively as managers of their own projects, are more informed than portfolio investors regarding the changes in prospects of their projects. This information enables them to manage their projects more efficiently. ${ }^{5}$ This effect generates an advantage, with an added value in the capital markets, to direct investments relative to portfolio investments.

However, there is also a disadvantage to the information that is gained by investing directly. In our model, investors sometimes need to sell their investments before maturity because they face liquidity shocks. In such circumstances, the price they can get will be lower if they have more information on the economic fundamentals of the investment project. This is because when potential buyers know that the seller has more information, they may suspect that the sale results from bad information on the prospects of the investment, and will thus be willing to pay a lower price. Thus, if they invest directly, the investors bear the cost of getting a lower price if and when they are forced to sell the project before maturity.

Our model, therefore, describes a key trade off between management efficiency and liquidity. ${ }^{6}$

\footnotetext{
${ }^{4}$ In this paper we focus on the differences between FDI and FPI. As we discuss in the concluding section of the paper, our approach can be easily extended to include debt flows as well.

${ }^{5}$ For a recent survey on agency problems and their effect on financial contracting, see: Hart (2000).

${ }^{6}$ Note that the interpretation of the word "liquidity" here is different from the one in the phrase "liquidity shock" . Here, "liquidity" means that when they invest in FDI, investors will face a less liquid market when they want to sell,
} 
Both sides of this trade off are driven by the effect of asymmetric information. When they invest directly, investors get more information about the fundamentals of the investment, and thereby can manage the project more efficiently, than their portfolio-investors counterparts. However, this also generates a "lemons" type problem when they try to sell the investment before maturity. Therefore, this superior information effect reduces the price they can get when they are forced to sell the project prematurely.

This trade off between efficiency and liquidity generates the differences between volatility of direct investment flows and volatility of portfolio investment flows: Investors with high expected liquidity needs are affected by the low price more than they are affected by the management efficiency, and thus, in equilibrium, will choose to become portfolio investors. Similarly, investors with low expected liquidity needs will choose to become direct investors. This is consistent with the casual observation that FDI investors are often large, deep-pocket, multinational companies with low expected liquidity needs, whereas FPI investors are, on average, more vulnerable to liquidity shocks. As a result, portfolio investments will be characterized by a higher probability of early liquidation, and greater volatility, compared to direct investments.

In order to demonstrate the basic point, we start by analyzing a simple model with a continuum of identical investors. Each investor has the same ex-ante probability of facing a liquidity shock, and this probability is known in the market. This model describes an industry that consists of investors with identical expected liquidity needs. We use the model to analyze the differences in direct-portfolio investment patterns across different industries; each industry is characterized by industry-specific expected liquidity needs. We show that when there are some fixed set-up costs to investing directly (e.g., costs of intra-firm coordination and acquiring information), industries in which investors are more vulnerable to liquidity risks, will be owned by portfolio investors. As a result, these industries will be characterized by higher probabilities of early liquidations and greater flow volatility.

Thus, this basic model demonstrates a key trade off between direct investment and portfolio investment. However, it also has two limitations: First, it cannot explain differences in volatility between direct investments and portfolio investments when the two types coexist in the same in the sense that they will get a lower price. A "liquidity shock" means that an investor is facing a shock that forces her to liquidate the investment. 
industry. ${ }^{7}$ Second, it understates the disadvantage of direct investments to investors with high expected liquidity needs. This is because the expected liquidity need of an individual investor is known in the market, and thus investors who have a high expected liquidity need do not get a very low price when they sell their direct investments prematurely, as potential buyers know that the sale is likely to be triggered by a liquidity shock and not by inferior information on the part of the owner. (This is also the reason for the result that investors with high expected liquidity needs choose portfolio investments only when there are some fixed set-up costs to direct investments.)

To relax these two limitations, we extend the basic model to include two types of investors. One type has a higher probability of getting a liquidity shock, and the other type has a lower probability of getting a liquidity shock. In this framework, the type of an individual investor is not necessarily known in the market. As a result, investors with high expected liquidity needs might be perceived as having low expected liquidity needs, and suffer from a very low price when they want to sell prematurely. This generates an additional force that pushes investors with a high probability of getting liquidity shocks to invest in portfolio investments: They try to separate themselves from the other type of investors. They do so by investing in portfolio investments, which work effectively as a signalling device.

As we show in the paper, in the model with heterogeneous investors, there exists a separating equilibrium (for some parameter values), in which investors with high expected liquidity needs invest only through portfolio investments, and investors with low expected liquidity needs invest only through direct investments. This may occur even with no fixed set-up costs associated with direct investments. This pattern can explain the differences between the proportion of reversals in the two types of investment.

Interestingly, for some parameter values, the model generates multiple equilibria: Either both types of investors choose direct investments (a pooling equilibrium), or investors with high expected liquidity needs choose portfolio investments, and investors with low expected liquidity needs choose direct investments (a separating equilibrium). This multiplicity of equilibria results from asymmetric-information externalities among investors with high expected liquidity needs: When more investors of their type choose direct investments, the re-sale price of these investments will increase, and the incentive of each investor of this type to choose these investments will increase. ${ }^{8}$

\footnotetext{
${ }^{7}$ Since investors in an industry are identical, they all choose the same type of investment in equilibrium.

${ }^{8}$ The forces that lead to the existence of a separating equilibrium and a pooling equilibrium here are similar to
} 
This multiplicity can explain why some countries have more direct investments than others, and why some periods of time are characterized by more direct investments than others. As we show in the paper, when the two equilibria exist, the host country benefits more under the pooling equilibrium than under the separating equilibrium. Thus, our model suggests a role for intervention to encourage investors to choose FDI rather than FPI. The mechanism here is very different than those that are discussed in the literature in association with the benefits of FDI to the host country.

Finally, we analyze the effect of transparency on the pattern of investments observed in equilibrium. Our motivation is twofold: First, we wish to explain why the differences in volatility between the two types of investment are smaller in developed economies than in developing economies. Second, the analysis of transparency is a natural extension of the model, as transparency mitigates asymmetric information, which is the source of the trade off in the model. We introduce two measures of transparency: Transparency between sellers and buyers, that we call capital-market transparency; and transparency between managers and owners (when the manager and the owner are not the same person), that we call corporate-governance transparency.

When the degree of capital-market transparency increases, buyers know more about the reason for a sale, when a sale takes place. This reduces the degree of asymmetric information, and thus reduces the disadvantage of direct investments. As a result, the likelihood of a separating equilibrium, in which investors with high expected liquidity needs choose portfolio investments, decreases. Thus, the model predicts that developed economies, in which capital-market transparency is expected to be higher, will have smaller differences between the volatility of portfolio investments, and the volatility of direct investments. When the degree of corporate-governance transparency increases, portfolio investors can sometime get information on the fundamentals of their projects, and manage them efficiently. They can also decide to sell them when they observe low realizations of the fundamentals. As a result, the differences between the two types of investment become smaller, and for some parameter values, the separating equilibrium is eliminated, generating a smaller difference between the volatilities of the two types of investment.

We now briefly indicate the relation between this paper and recent literature. The literature on FDI is vast and covers many issues related to FDI. For a good literature survey, see Bayoumi and Lipworth (1997). Most of the papers in this literature, however, do not analyze differences those in Stiglitz (1975). 
in volatility between FDI and FPI. One explanation that is often mentioned to the difference in volatility between the two types of investment relies on the assumption that direct investments are irreversible for some exogenous reason (for example: High exit costs). However, as Albuquerque (2002) suggests, this argument has two main drawbacks: First, withdrawals of direct investments do not necessarily have to include liquidation of physical capital, and in fact, firms have many other ways to withdraw funds that were invested as direct investment (for example, selling shares). ${ }^{9}$ Second, in times of a crisis, not only FDI, but also other types of flows might dry up, and thus the relative stability of FDI remains a puzzle. Importantly, the liquidity of each type of investment is endogenous in our model. In addition, our model sheds light on the difference in the volatility ratio between developed economies and developing economies, and this cannot be explained when FDI is assumed to be irreversible or to have higher costs of exit. Albuquerque (2002) develops a model aimed at explaining differences between the volatility of direct investments and the volatility of portfolio investments. His paper relies on expropriation risks and the inalienability of direct investments, and thus is different from the information-based mechanism developed here.

Some papers in the literature use the asymmetric information hypothesis to address different issues related to FDI. In Froot and Stein (1991), Klein and Rosengren (1994), and Klein, Peek and Rosengren (2002), the hypothesis is that FDI is information intensive, and thus FDI investors, who know more about their investments than outsiders, face a problem in raising resources for their investments. Gordon and Bovenberg (1996) assume asymmetric information between domestic investors and foreign investors to explain the home bias phenomenon. Razin, Sadka and Yuen (1998) explain the pecking order of international capital flows with a model of asymmetric information. Finally, Razin and Sadka (2003) analyze the gains from FDI when foreign direct investors have superior information on the fundamentals of their investment, relative to foreign portfolio investors. Importantly, none of these papers analyzes the effects of asymmetric information on the liquidity and the volatility of FDI and portfolio investments.

Although we write this paper in the context of international capital flows, we believe the mechanism we suggest here is more general, and can serve to analyze the trade off between direct investments and portfolio investments, or between management efficiency and liquidity, in other contexts. ${ }^{10}$ In a related paper, Bolton and von-Thadden (1998) analyze a trade off between direct

\footnotetext{
${ }^{9}$ For more details on this point, see Albuquerque (2002) and Hausman and Fernandez-Arias (2000).

${ }^{10}$ The model is especially relevant in the context of international flows because there is a strong empirical evidence
} 
investments and portfolio investments. Their model, however, is not based on the differences in information that each one of these investments provides. They also do not analyze the volatility of different investments in equilibrium. To the best of our knowledge, our paper is the first paper that looks at an information-based trade off between direct investments and portfolio investments, and analyzes the effect of this trade off on the volatility of the different investments. ${ }^{11}$ Our paper also touches on other issues that have been discussed in the finance literature. Admati and Pfleiderer (1991) discuss the incentive of traders to reveal the fact that they are trading for liquidity reasons and not because of bad information. Admati and Pfleiderer (1988) and Foster and Viswanathan (1990) point to the existence of externalities between traders who trade for liquidity reasons.

The remainder of this paper is organized as follows: Section 2 presents the basic model with one type of investor. In Section 3, we study the basic trade off between direct investments and portfolio investments, and determine the type of investment that is chosen in equilibrium in different industries. In Section 4, we study the implications of our model for the probabilities of early withdrawals of direct investments and portfolio investments. In Section 5, we extend the model, and analyze the pattern of investments and withdrawals when there are two types of investors. We use this framework to study welfare implications. Section 6 studies the effect of transparency on investment patterns in equilibrium. Section 7 concludes, and highlights additional implications of our model. Proofs are relegated to the Appendix.

\section{Analytical Framework}

A small economy is faced by a continuum $[0,1]$ of foreign investors. Each investor has an opportunity to invest in one investment project. Investment can occur in two forms. The first form is a direct investment (FDI). The second form is a portfolio investment. The only difference between the two forms of investment is that a direct investor will effectively act like a manager, whereas in case of a portfolio investment, the investor will not be the manager, and the project will be managed by on volatility of international flows, which can be explained by our trade off.

${ }^{11}$ Two other related papers are Kahn and Winton (1998) and Maug (1998). In these papers, the information held by institutional investors does not always improve the value of the firm, as institutional investors might use this information to make trading profits instead of to improve firm performance. These models do not look, however, at the decision of the investors on whether to acquire information when they might get liquidity shocks. 
an "outsider". We assume that investors are risk neutral, and thus each investor chooses the form of investment that maximizes her ex-ante expected payoff.

There are three periods of time: 0,1 , and 2 . In period 0 , each investor decides whether to make a direct investment or a portfolio investment. In period 2 , the project matures. The payoff from the project is denoted as $R$, where $R$ is given by:

$$
R=(1+\varepsilon) k-\frac{1}{2} A k^{2}
$$

Here, $\varepsilon$ denotes a random productivity factor (technology shock) that is independently realized for each project in period $1 ; k$ is the level of capital input invested in the project in period 1 , after the realization of $\varepsilon$. We assume that $\varepsilon$ is distributed between -1 and 1 according to a cumulative distribution function $G(\cdot)$ and a density function $g(\cdot)=G^{\prime}(\cdot)$. We also assume that $E(\varepsilon)=0 .{ }^{12}$

\subsection{Management and Efficiency}

In period 1, after the realization of the technology shock, the manager of the project observes $\varepsilon$. Thus, if the investor owns the project as a direct investment, she observes $\varepsilon$, and chooses $k$, so as to maximize the payoff. The chosen level of $k$ will then be equal to $k^{*}(\varepsilon)$, which is given by:

$$
k^{*}(\varepsilon)=\frac{1+\varepsilon}{A} .
$$

Thus, the ex-ante expected payoff from a foreign direct investment if it is held until maturity is given by:

$$
E\left(\frac{(1+\varepsilon) \cdot(1+\varepsilon)}{A}-\frac{1}{2} A\left(\frac{1+\varepsilon}{A}\right)^{2}\right)=\frac{E\left((1+\varepsilon)^{2}\right)}{2 A} .
$$

In case of a portfolio investment, the owner is not the manager, and thus she does not observe $\varepsilon$. In this case, the manager follows earlier instructions as for the level of $k$. A possible rationale behind this sequence of firm decisions, whereby the level of capital input $k$ is determined ex ante, has to do with a potential agency problem between the owner and the manager (who is responsible for making these decisions). Loosely speaking, the latter is not exclusively interested in the net worth of the firm as is the former. For example, with no explicit instructions at hand, the manager

\footnotetext{
${ }^{12}$ Our results hold for more general speicifications. We use this specification to simplify the exposition.
} 
may wish to set $k$ at the highest possible level in order to gain power. As a result, when the owner does not have information about the firm's productivity, she will have to set investment guidelines for the manager (who knows more about $\varepsilon$ than she does) so as to protect her own interests. ${ }^{13}$ This agency problem is not modelled explicitly here because we want to focus instead on its implications for the trade off between direct investments and portfolio investments. What we do, however, capture in our model is the spirit of the agency problem, and the inefficiency associated with the fact that the owner of the project is not the manager.

The earlier instruction is chosen by the owner to maximize the expected return absent any information on the realization of $\varepsilon$, and is based on the ex ante mean of $\varepsilon$ : 0 . Thus, the manager will be instructed to choose $k=k^{*}(0)=\frac{1}{A} \cdot{ }^{14}$ Then, the ex-ante expected payoff from a portfolio investment if it is held until maturity is:

$$
E\left(\frac{(1+\varepsilon)}{A}-\frac{1}{2 A}\right)=\frac{E(1+2 \varepsilon)}{2 A}=\frac{1}{2 A} .
$$

Comparing (3) with (4), we see that if the project is held until maturity, it yields a higher payoff as a direct investment than as a portfolio investment. This result reflects the efficiency that results from a hands-on management style in the case of a direct investment. The disadvantage of direct investment will follow from the possibility of a liquidity shock in period 1 .

\section{2 liquidity Shocks and Resales}

In period 1, before the value of $\varepsilon$ is known to those who will be later informed about it, the owner of the project gets a liquidity shock with probability $\lambda(0<\lambda<1) .{ }^{15}$ An investor that got a liquidity

\footnotetext{
${ }^{13}$ The arg ument, according to which the manager wishes to make larger investments and build an empire is common in the corporate finance literature. In such a case, if the owner cannot verify the information that the manager had at the time of the decision, she will not be able to prove that the manager acted to maximize his own objective function. As a result, a contract that instructs the manager to maximize the value of the firm given his information will not be enforceable.

${ }^{14}$ The current specification, according to which the owner of a portfolio investment receives no information on the realization of $\varepsilon$, and thus instructs the manager to choose $k$ according to the ex-ante mean of $\varepsilon$ is simple and is intended to capture the spirit of the inefficiency. The result will hold under more complicated specifications. For example, in Section 6 we study an extension, in which the owner observes $\varepsilon$ with some probability.

${ }^{15}$ Recall that in this section we analyze a model where all the investors have the same $\lambda$. This assumption is relaxed in Section 5.
} 
shock needs to sell the project in period 1. The underlying assumption behind this sequence is similar to the assumption made by Diamond and Dybvig (1983): An investor that got a liquidity shock, derives utility only from period-1 consumption. If she does not get a liquidity shock, she derives utility from period-2 consumption. As a result, an investor that got a liquidity shock will sell the project in period 1 , as she cannot wait to collect the payoff in period 2. The project can be sold to outside investors, who are not informed about $\varepsilon$, but are familiar with the other parameters of the problem.

There is also a possibility that an investor will sell her project in period 1 absent a liquidity shock. This will happen if and only if she observes a low realization of $\varepsilon$, in which case she has superior information over the buyer, and can exploit it. Since portfolio investors do not observe $\varepsilon$ in period 1, only direct investors will sell the project at that time absent a liquidity shock. ${ }^{16}$ All kind of sales in period 1 occur simultaneously. Thus, buyers do not know the reason for a sale of an individual project. They only know whether the project that is being sold was owned as a direct investment or as a portfolio investment. Thus, and because only direct investments are sold due to low productivity shocks, the price that direct investors can get when they try to sell the project in period 1 will be lower.

We now derive the price that a direct investor gets if she sells the project in period 1 . This price is equal to the expected value of the project from the point of view of the buyer, given that the buyer knows that the owner is trying to sell, and given that she does not know the reason for the sale. We denote the threshold level of $\varepsilon$, under which the direct investor is selling the project without a liquidity shock as $\varepsilon_{D}$. Then, the buyer knows that with probability $(1-\lambda) G\left(\varepsilon_{D}\right)$, the owner is selling the project because of a low realization of $\varepsilon$, whereas with probability $\lambda$, she is selling it because of a liquidity shock.

As we noted above, liquidity shocks are realized before productivity shocks. We thus assume that if the project is sold because of a liquidity shock (that is, before the realization of $\varepsilon$ is revealed to the owner), the value of $\varepsilon$ is not recorded in the firm before the sale, and the new owner will not know the value of $\varepsilon$ after the sale. However, if the project is sold because of a low realization

\footnotetext{
${ }^{16}$ This is again a result of our specification, in which the owner of a portfolio investment receives no information on the realization of $\varepsilon$ in period 1 . The result will hold in more general specifications; see for example the second extension in Section 6 .
} 
of the technology parameter, the new owner will know the value of $\varepsilon$ after the sale. Note that this is just an assumption regarding the technical details of the sale in period 1, and that our analysis will not qualitatively change if we adopt another assumption.

Using Bayes' rule, the price that the direct investor gets for the project in period 1 is given by:

$$
P_{1, D}=\frac{(1-\lambda) \int_{-1}^{\varepsilon_{D}} \frac{(1+\varepsilon)^{2}}{2 A} g(\varepsilon) d \varepsilon+\lambda \int_{-1}^{1} \frac{1+2 \varepsilon}{2 A} g(\varepsilon) d \varepsilon}{(1-\lambda) G\left(\varepsilon_{D}\right)+\lambda} .
$$

The owner, in turn, sets $\varepsilon_{D}$, such that given $P_{1, D}$, when observing $\varepsilon_{D}$, she will be indifferent between selling the project and not. This yields the following equation:

$$
P_{1, D}=\frac{\left(1+\varepsilon_{D}\right)^{2}}{2 A}
$$

Thus, equations (5) and (6) determine $P_{1, D}$ and $\varepsilon_{D}$. We show in the Appendix that for each $\lambda$ between 0 and 1 , there is a unique solution for $\varepsilon_{D}$ (denoted as $\varepsilon_{D}(\lambda)$ ) between -1 and 0 . As a result there is also a a unique solution for $P_{1, D}\left(\right.$ denoted as $\left.P_{1, D}(\lambda)\right)$. Importantly, $\varepsilon_{D}(\lambda)$ and $P_{1, D}(\lambda)$ are increasing in $\lambda$ : When $\lambda$ is higher, the probability that an early sale results from a liquidity shock (and not from a bad realization of the technology parameter) is higher, and the price of the project in period 1 increases.

As for the portfolio investor, if she sells the project in period 1, everybody knows she does it because of a liquidity shock. Thus, the price she gets for the project is given by:

$$
P_{1, P}=\int_{-1}^{1} \frac{1+2 \varepsilon}{2 A} g(\varepsilon) d \varepsilon=\frac{1}{2 A} .
$$

Solving for $P_{1, D}$ and $\varepsilon_{D}$, we can see that $\varepsilon_{D}<0$, and thus that $P_{1, D}<\frac{1}{2 A}$. Thus, the price of a direct investment in period 1 is lower than the price of a portfolio investment in this period. The reason is that when the direct investor tries to sell the project, the price will reflect the possibility that the sale originates from bad information on the prospects of the investment project.

\section{The Basic trade off between Direct Investment and Portfolio Investment}

Following the discussion in the last section, we see that there is a trade off between holding the project as a direct investment and holding it as a portfolio investment. On one hand, a direct 
investment enables the investor to manage the project more efficiently. This increases the return that she gets in case she does not have to sell early. On the other hand, when she holds the project as a direct investment, the investor will get a lower price for the project if she sells it in the short term. This is because potential buyers know that with some probability the project is being sold because of bad information on the prospects of the investment. Thus, the additional information that is associated with a direct holding of the investment is not necessarily beneficial, as it harms the investor when she tries to sell the project early. In this section, we study the differences between the expected payoffs under the two forms of investment when all the investors have the same $\lambda$.

We start with the direct investment. In this case, with probability $\lambda$, the investor gets a liquidity shock, and sells the project in period 1 . Then, her payoff is:

$$
P_{1, D}(\lambda)=\frac{\left(1+\varepsilon_{D}(\lambda)\right)^{2}}{2 A}
$$

With probability $1-\lambda$, the investor does not get a liquidity shock. Then, she will sell the project if the realization of $\varepsilon$ is below $\varepsilon_{D}(\lambda)$, and she will not sell it if the realization of $\varepsilon$ is above $\varepsilon_{D}(\lambda) .\left(\varepsilon_{D}(\lambda)\right.$ is determined by equations (5) and (6)). The total expected payoff in this case can thus be written as:

$$
\int_{-1}^{\varepsilon_{D}(\lambda)} \frac{\left(1+\underline{\varepsilon}_{D}(\lambda)\right)^{2}}{2 A} g(\varepsilon) d \varepsilon+\int_{\underline{\varepsilon}_{D}(\lambda)}^{1} \frac{(1+\varepsilon)^{2}}{2 A} g(\varepsilon) d \varepsilon
$$

Thus, the ex ante expected payoff from a direct investment is given by:

$$
E V_{\text {Direct }}(\lambda)=\lambda \frac{\left(1+\underline{\varepsilon}_{D}(\lambda)\right)^{2}}{2 A}+(1-\lambda)\left(\begin{array}{c}
\int_{-1}^{\varepsilon_{D}(\lambda)} \frac{\left(1+\varepsilon_{D}(\lambda)\right)^{2}}{2 A} g(\varepsilon) d \varepsilon \\
+\int_{\varepsilon_{D}(\lambda)}^{1} \frac{(1+\varepsilon)^{2}}{2 A} g(\varepsilon) d \varepsilon
\end{array}\right) .
$$

We now derive the ex ante expected payoff from a portfolio investment. When the investor holds the investment as a portfolio investment, with probability $\lambda$, she receives a liquidity shock, and sells the project in period 1 . Then, her payoff is:

$$
P_{1, P}=\frac{1}{2 A}
$$

With probability $1-\lambda$, the investor does not receive a liquidity shock. Then, her expected payoff is: 


$$
\frac{E(1+2 \varepsilon)}{2 A}=\frac{1}{2 A}
$$

Thus, the ex ante expected payoff from a portfolio investment is given by:

$$
\text { EV } V_{\text {Portfolio }}=\frac{1}{2 A} \text {. }
$$

In order to determine whether, in period 0 , investors choose a direct investment or a portfolio investment, we need to compare $E V_{\text {Direct }}(\lambda)$ with $E V_{\text {Portfolio. At this point, we make an additional }}$ assumption: We assume that, in period 0, there is an additional cost to make a direct investment. This represents the initial cost of acquiring information via a direct investment. We denote this cost as $c$. Then, it is clear that, in period 0 , investors will choose a direct investment if:

$$
\operatorname{Dif}(\lambda) \equiv E V_{\text {Direct }}(\lambda)-E V_{\text {Portfolio }}>c .
$$

Similarly, they will choose a portfolio investment if:

$$
\operatorname{Dif}(\lambda) \equiv E V_{\text {Direct }}(\lambda)-E V_{\text {Portfolio }}<c .
$$

Proposition 1 studies the properties of the function $\operatorname{Dif}(\lambda) .{ }^{17}$

Proposition 1 For any $\lambda$ between 0 and 1, Dif $f^{\prime}(\lambda)<0$. Moreover, Dif $(1)=0$, and Dif $(0)>0$.

We now explain the intuition behind the proposition. When $\lambda=1$, the investors know they will have to sell the project in period 1. Thus, the (gross) return they get on the investment is the price they will get in period 1. Moreover, when they sell in period 1, the price is not adjusted to reflect any information on the prospects of the project. This is because potential buyers know that the sale is a result of a liquidity shock. As a result, in this case the expected return on a direct investment is equal to the return on a portfolio investment.

As $\lambda$ decreases from 1 to 0 , there are two opposite effects on the value of $\operatorname{Dif}(\lambda)$. First, agents know that with a higher probability, they will not observe a liquidity shock, and thus will continue to own the project until maturity. As a result, they value more the higher efficiency that results from

\footnotetext{
${ }^{17}$ Clearly, if $\operatorname{Dif}(\lambda) \equiv E V_{\text {Direct }}(\lambda)-E V_{\text {Portfolio }}=c$, the investors will be indifferent between the two types of investment. We ignore this case here.
} 
more information, and care less about the lower period-1 price that results from this information.

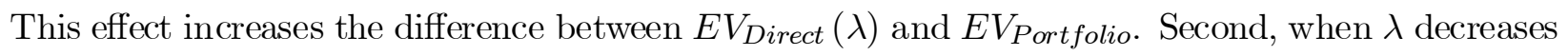
from 1 to 0 , the period- 1 price will be lower if a direct investor tries to sell. This is because potential buyers know that the sale is more likely to reflect bad information about the prospects of the investment and less likely to reflect a liquidity shock. This effect reduces the difference between $E V_{\text {Direct }}(\lambda)$ and $E V_{\text {Portfolio }}$. According to Proposition 1 the first effect is stronger than the second effect. As a result, $\operatorname{Dif}(\lambda)<0$. Finally, following the above analysis, we can tell that $\operatorname{Dif}(0)>0$.

In Proposition 2, we study the optimal investment vehicle that is chosen in period 0.

Proposition 2 If $c \geq D i f(0)$, investors will always choose a portfolio investment in period 0. If $c=0$, investors will always choose a direct investment in period 0 . If $0<c<\operatorname{Dif}(0)$, there is a threshold level of $\lambda: \lambda^{*}(c)\left(0<\lambda^{*}(c)<1\right)$, such that if $\lambda<\lambda^{*}(c)$, investors will choose a direct investment in period 0 , and if $\lambda>\lambda^{*}(c)$, investors will choose a portfolio investment in period 0 .

The intuition behind Proposition 2 is straightforward given Proposition 1. We thus get that when $c$ is in an intermediate range, a direct investment will occur if and only if the probability of observing a liquidity shock is below a certain threshold. Figure 1 demonstrates the choice between direct investments and portfolio investments.

Note that in the current model, investors choose portfolio investments only when $c>0$. This is a result of the fact that the specification with homogeneous investors understates the disadvantage of direct investments to investors with high expected liquidity needs. We address this issue in Section 5, when we analyze a model with heterogeneous investors.

\section{The Probability of Midstream Sales of the Investment Project}

On the basis of the trade off between the two types of investment, we analyze the probability that foreign investors will sell their investment in period 1, and withdraw their money out of the economy before the maturity of the investment. In case of a direct investment, this probability is given by:

$$
\lambda+(1-\lambda) G \underline{\varepsilon}_{D}((\lambda)),
$$




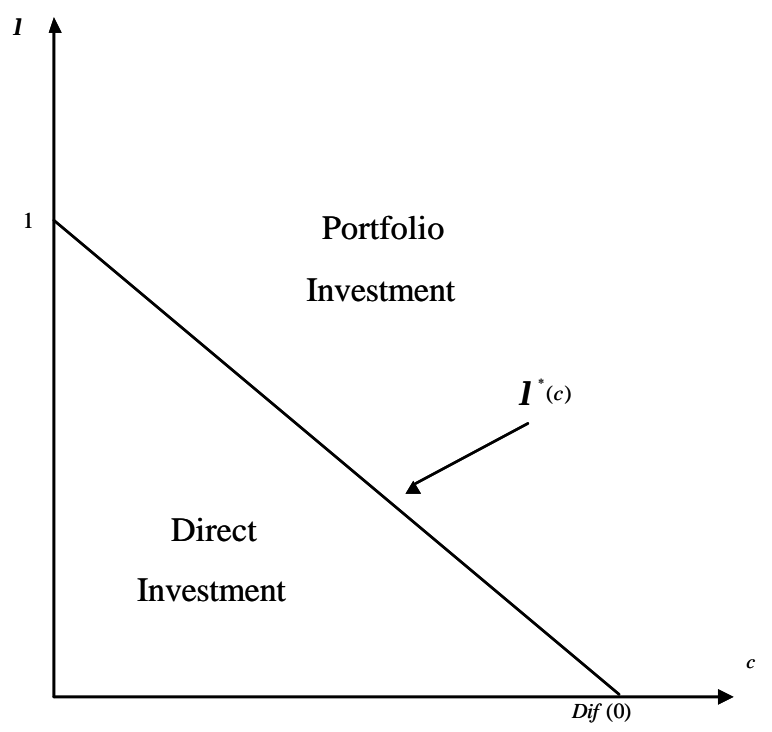

Figure 1: The Choice between Direct Investment and Portfolio Investment

where $\lambda$ is the probability of a sale that results from a liquidity shock, and $(1-\lambda) G \varepsilon_{D}(\lambda)$ is the probability of a sale that results from a technology shock. In case of a portfolio investment, an early sale can result only from a liquidity shock, and thus the probability of an early sale is simply given by:

$\lambda$.

We now consider two industries. One industry is characterized by a lower probability of liquidity shocks (a lower $\lambda$ ), and the other is characterized by a higher probability of liquidity shocks (a higher $\lambda)$. Both industries are characterized by the same cost of acquiring information ( $c$ is the same). Suppose that the differences between the two industries are such that in the first industry, investors invest via a direct investment, and in the second industry they invest via a portfolio investment (that is, in the first industry, $\lambda<\lambda^{*}(c)$, and in the second industry, $\lambda>\lambda^{*}(c)$ ). What will be the difference between the probabilities of early sales in the two industries? Here, there are two effects. First, the higher probability of a liquidity shock in the industry with portfolio investments generates a higher probability of an early sale in this industry. Second, the possibility of a sale that is based on a technology shock exists only in the industry with direct investments. This effect pushes up the 
probability of an early sale in the industry with direct investments. When the differences between the $\lambda$ 's in the two industries are large enough, the probability of an early sale in the industry with portfolio investments will be higher.

In Table 1, we present the results of a numerical example of our model. For the purpose of this example, we assume that $\varepsilon$ is uniformly distributed between -1 and 1 , and that $A=0.5$. Table 1 shows the optimal type of investment and the probability of an early sale for different levels of $\lambda$, and for different levels of $c$. In the table, the optimal type of investment is determined according to the rule in Proposition 2. Then, the probability of an early sale is equal to $\lambda$ in case of a portfolio investment, and is equal to $\left.\lambda+(1-\lambda) G \varepsilon_{D}(\lambda)\right)$ in case of a direct investment.

\begin{tabular}{||c||c||c|c||c|c||}
\hline \hline$\lambda$ & \multicolumn{1}{||c||}{$\varepsilon_{D}(\lambda)$} & \multicolumn{2}{c||}{$c=0.1$} & \multicolumn{2}{c||}{$c=0.2$} \\
\hline \hline & & Investment & Probability of Early Sale & Investment & Probability of Early Sale \\
\hline 0.1 & -0.40 & Direct & 0.37 & Direct & 0.37 \\
\hline 0.2 & -0.28 & Direct & 0.49 & Direct & 0.49 \\
\hline 0.3 & -0.21 & Direct & 0.58 & Direct & 0.58 \\
\hline 0.4 & -0.16 & Direct & 0.65 & Direct & 0.65 \\
\hline 0.5 & -0.12 & Direct & 0.72 & Portfolio & 0.5 \\
\hline 0.6 & -0.09 & Direct & 0.78 & Portfolio & 0.6 \\
\hline 0.7 & -0.06 & Direct & 0.84 & Portfolio & 0.7 \\
\hline 0.8 & -0.04 & Portfolio & 0.8 & Portfolio & 0.8 \\
\hline 0.9 & -0.02 & Portfolio & 0.9 & Portfolio & 0.9 \\
\hline \hline
\end{tabular}

Table 1: Numerical Example - Probabilities of Early Sales

Using the table, we compare the probabilities of early sales between two industries that have different levels of $\lambda$, but the same level of $c$. We can see that in most cases, when the differences between the $\lambda$ 's in the two industries are large enough, the industries that have portfolio investments will have a higher probability of an early sale. The opposite case will hold only when the levels of $\lambda$ in the two industries are very close.

In the remainder of the paper, when we analyze the reversals of the two types of investment, we consider only the reversals that result from liquidity shocks. This is because of two reasons. One, as we saw in Table 1, the liquidity shock is usually the dominant effect behind the differences 
in the amount of reversals. Two, according to many commentators, the volatility of international flows around crisis times is usually not associated with bad fundamentals, but rather with some shortage in liquidity. Thus, in this paper, we are more interested in reversals that are driven by liquidity shocks.

To sum up, on the basis of Proposition 2, we know that industries with a high probability of liquidity shocks are more likely to have portfolio investments. As a result, we can explain the higher probability of an early withdrawal of portfolio investments: Since these investments are owned by investors that are more vulnerable to a liquidity risk, they will be liquidated more often. This will lead to a higher volatility of portfolio investments.

\section{$5 \quad$ Heterogeneous Investors}

So far we have analyzed an economy (industry), where all the investors had the same probability of getting a liquidity shock. This framework was efficient in demonstrating the basic trade off between direct investments and portfolio investments. However, it also had two main limitations: One, in equilibrium, all the investors in the economy (industry) followed the same investment strategy. Thus, we could not analyze the differences in volatility between direct investments and portfolio investments, when both of them coexist. Two, since all the investors were identical, the probability that an individual investor got a liquidity shock was known to potential buyers. This limited the disadvantage of direct investments: Investors with a very high $\lambda$, who have the lowest benefit from direct investments, expected that if they sell a direct investment in period 1 , the price will not be very low, as the market knows their $\lambda$, and thus assesses a high probability that the sale results from a liquidity shock. As a result, even for these investors, portfolio investments dominated direct investments only when we introduced a fixed positive cost $c$ to investing directly.

We now extend the model to allow for two types of investors in an economy (industry). We will analyze the pattern of investments and withdrawals when the two types of investors coexist. As we will see, this extension sheds light on other effects that determine the pattern of investments and withdrawals. It will also generate an interesting welfare analysis. The main difference in the analysis results from the fact that when different investors have different $\lambda$ 's, it is not always known in the market what is the $\lambda$ of each individual investor. As a result, when they want to sell a project 
in period 1, investors will sometimes face a price that does not reflect their true $\lambda$. This may create an incentive to signal the true $\lambda$ by choosing an investment vehicle.

\subsection{The New Framework}

Suppose again that there is a continuum $[0,1]$ of investors in the economy. Proportion $\frac{1}{2}$ of them have high expected liquidity needs, and proportion $\frac{1}{2}$ have low expected liquidity needs. Formally, assume that the first type of agents face a liquidity need with probability $\lambda_{H}$, whereas the second type of agents face a liquidity need with probability $\lambda_{L}$. For simplicity, we assume that $1>\lambda_{H}>$ $\frac{1}{2}>\lambda_{L}>0$, and that $\frac{\lambda_{H}+\lambda_{L}}{2}=\frac{1}{2}$. We also assume that $c=0 .{ }^{18}$ Investors know their type ex ante, however this is their private information.

The existence of heterogeneous investors does not affect the payoffs from portfolio investments. Since owners of portfolio investments never observe $\varepsilon$, they sell the project in period 1 only when they get a liquidity shock. Since this is known to potential buyers, the price they will pay for a portfolio investment in period 1 is $\frac{1}{2 A}$, as we had in (7). Similarly, the ex-ante expected payoff from a portfolio investment is $\frac{1}{2 A}$, as we had in (9).

However, the expected payoffs from direct investments change. When there are heterogeneous investors, potential buyers do not know the type of an individual investor. As a result, the ex ante probability that an individual investor gets a liquidity shock may be different from the probability that is perceived by the market. The price of direct investments in period 1 , and the threshold level of $\varepsilon$, below which investments are sold, will depend on the probability that is perceived by the market. Denoting the probability of a liquidity shock for an individual investor as $\lambda_{i}$, and the probability that is perceived by the market as $\lambda_{m}$, we get that the expected payoff from a direct investment for this individual investor is $E V_{2, \text { Direct }}\left(\lambda_{i}, \lambda_{m}\right)$, where:

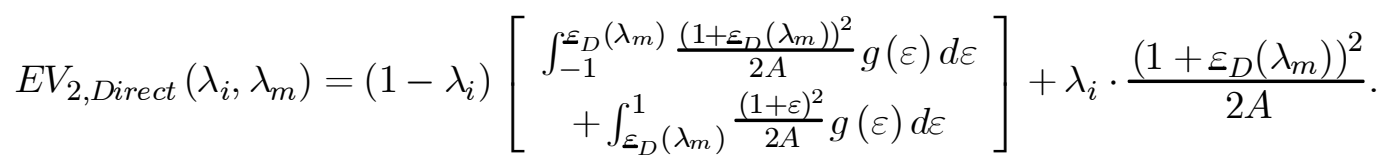

In this expression, the value of $\varepsilon_{D}\left(\lambda_{m}\right)$ is determined according to (5) and (6). Recall that $\varepsilon_{D}\left(\lambda_{m}\right)$ is increasing in $\lambda_{m}$. Thus, in this framework, investors have an incentive to signal that they have a high $\lambda$. This point and the fact that $\lambda_{m}$ may be different from $\lambda_{i}$ will have an important effect on the type of investment that will be chosen in equilibrium.

\footnotetext{
${ }^{18}$ Note that our results hold in a more general setting, for any $\lambda_{H}>\lambda_{L}$, and for $c>0$.
} 


\subsection{Symmetric Equilibria}

We analyze symmetric equilibria, i.e. equilibria in which agents of the same type choose the same type of investment. There are four potential equilibria, to which we refer here as four different cases: 1. All investors invest in direct investments. 2. All investors invest in portfolio investments. 3. $\lambda_{H}$ investors invest in portfolio investments, and $\lambda_{L}$ investors invest in direct investments. 4 . $\lambda_{H}$ investors invest in direct investments, and $\lambda_{L}$ investors invest in portfolio investments. Towards the end of the section, we analyze the possibility of existence of other (non-symmetric) equilibria.

We start by analyzing the conditions that are required to establish each one of the four cases as an equilibrium. Then, we characterize the equilibrium outcomes under different parameter values.

\section{Case 1: Both $\lambda_{H}$ and $\lambda_{L}$ investors invest in direct investments}

In this case, in the proposed equilibrium, when an investor wants to sell her project in period

1, potential buyers assess a probability of $\frac{1}{2}$ that the investor is trying to sell because of a liquidity need. This is because all the investors use the same investment vehicle, and thus in case of an early sale, potential buyers do not know the type of the investor that is trying to sell (recall that $\left.\frac{\lambda_{H}+\lambda_{L}}{2}=\frac{1}{2}\right)$. Thus, both types of investors will sell because of bad information when they observe a signal telling them that $\varepsilon<\varepsilon_{D}\left(\frac{1}{2}\right)$. The price they will get will be: $\frac{\left(1+\varepsilon_{D}\left(\frac{1}{2}\right)\right)^{2}}{2 A}$. If an investor diverged from this proposed equilibrium strategy and invested in a portfolio investment, potential buyers would know that if she sells the project it is because of a liquidity shock. Then, the price she will get will be: $\frac{1}{2 A}$. In equilibrium, $\lambda_{H}$ investors invest in a direct investment if the following condition holds:

$$
E V_{2, \text { Direct }}\left(\lambda_{H}, \frac{1}{2}\right) \geq \frac{1}{2 A}
$$

A similar condition applies for $\lambda_{L}$ investors:

$$
E V_{2, \text { Direct }}\left(\lambda_{L}, \frac{1}{2}\right) \geq \frac{1}{2 A} \text {. }
$$

\section{Case 2: Both $\lambda_{H}$ and $\lambda_{L}$ investors invest in portfolio investments}

In this case, in the proposed equilibrium, there are only portfolio investments, and thus investors sell their project in period 1 only because of a liquidity shock. If an investor diverges from this equilibrium and holds a direct investment, she may try to sell in period 1 following a low realization of $\varepsilon$. In this case, given that the equilibrium behavior of all the investors is identical, potential buyers 
will not know her type, and the price she will get will be: $\frac{\left(1+\varepsilon_{D}\left(\frac{1}{2}\right)\right)^{2}}{2 A}$. As a result, the conditions that we need in order to establish this case as an equilibrium, are the opposite conditions than the ones we had in case 1 :

$$
\begin{aligned}
& E V_{2, \text { Direct }}\left(\lambda_{H}, \frac{1}{2}\right) \leq \frac{1}{2 A}, \\
& E V_{2, \text { Direct }}\left(\lambda_{L}, \frac{1}{2}\right) \leq \frac{1}{2 A} .
\end{aligned}
$$

Case 3: $\lambda_{H}$ investors invest in portfolio investments, $\lambda_{L}$ investors invest in direct investments

In this case, in the proposed equilibrium, there is separation between $\lambda_{H}$ investors and $\lambda_{L}$ investors. Thus, when a $\lambda_{L}$ investor wants to sell her direct investment in period 1, potential buyers know her type, and assess a probability of $\lambda_{L}$ that she is selling because of a liquidity need. $\lambda_{H}$ investors, who follow the proposed-equilibrium strategy and invest in portfolio investments, will get a price of $\frac{1}{2 A}$ in case they sell in period 1 . However, if a $\lambda_{H}$ investor diverges from the equilibrium strategy and invests in a direct investment, potential buyers will think she is a $\lambda_{L}$ investor, and then when she tries to sell, the price she will get will be $\frac{\left(1+\underline{\varepsilon}_{D}\left(\lambda_{L}\right)\right)^{2}}{2 A}$. Note that this price is lower than $\frac{\left(1+\varepsilon_{D}\left(\lambda_{H}\right)\right)^{2}}{2 A}$ and lower than $\frac{\left(1+\varepsilon_{D}\left(\frac{1}{2}\right)\right)^{2}}{2 A}$. Thus, a $\lambda_{H}$ investor is punished when she diverges from the equilibrium strategy. The condition, under which $\lambda_{H}$ investors will invest in a portfolio investment, is:

$$
E V_{2, \text { Direct }}\left(\lambda_{H}, \lambda_{L}\right) \leq \frac{1}{2 A}
$$

Similarly, the condition, under which $\lambda_{L}$ investors will invest in a direct investment, is:

$$
E V_{2, \text { Direct }}\left(\lambda_{L}, \lambda_{L}\right) \geq \frac{1}{2 A}
$$

Case 4: $\lambda_{H}$ investors invest in direct investments, $\lambda_{L}$ investors invest in portfolio investments

Following the same line of argument that we used in Case 3, we derive the conditions, under which this equilibrium can hold. The condition for $\lambda_{H}$ investors is:

$$
E V_{2, \text { Direct }}\left(\lambda_{H}, \lambda_{H}\right) \geq \frac{1}{2 A} .
$$


The condition for $\lambda_{L}$ investors is:

$$
E V_{2, \text { Direct }}\left(\lambda_{L}, \lambda_{H}\right) \leq \frac{1}{2 A}
$$

\subsection{Equilibrium Outcomes}

Proposition 3 characterizes the equilibrium outcomes under different parameter values. The characterization of equilibrium outcomes is based on two threshold values of $\lambda_{H}$, which are defined below:

$\lambda_{H}^{*}$ is given by: $\left(\right.$ Here, $\left.\lambda_{L}^{*} \equiv\left(1-\lambda_{H}^{*}\right)\right)$

$$
E V_{2, \text { Direct }}\left(\lambda_{H}^{*}, \lambda_{L}^{*}\right)=\frac{1}{2 A},
$$

and $\lambda_{H}^{* *}$ is given by:

$$
E V_{2, \text { Direct }}\left(\lambda_{H}^{* *}, \frac{1}{2}\right)=\frac{1}{2 A} .
$$

As we show in the proof of Proposition 3 in the Appendix, $\frac{1}{2}<\lambda_{H}^{*}<\lambda_{H}^{* *}<1$.

Proposition 3 When $\frac{1}{2}<\lambda_{H}<\lambda_{H}^{*}$, only Case 1 is an equilibrium. That is, both $\lambda_{H}$ and $\lambda_{L}$ investors invest in direct investments.

When $\lambda_{H}^{*} \leq \lambda_{H} \leq \lambda_{H}^{* *}$, both Case 1 and Case 3 are equilibria. That is, either both $\lambda_{H}$ and $\lambda_{L}$ investors invest in direct investments, or $\lambda_{H}$ investors invest in portfolio investments and $\lambda_{L}$ investors invest in direct investments.

When $\lambda_{H}^{* *}<\lambda_{H}<1$, only Case 3 is an equilibrium. That is, $\lambda_{H}$ investors invest in portfolio investments and $\lambda_{L}$ investors invest in direct investments.

Interestingly, in contrast to the model with homogeneous investors, here we have an equilibrium, in which some investors choose direct investments, whereas others choose portfolio investments. Moreover, here, investors choose portfolio investments even if there is no immediate cost associated with the direct investments $(c=0)$. As we noted above, the main difference between the current model and the model discussed in the previous sections is that here potential buyers do not know the type of an individual investor. As a result, an investor with a very high expected liquidity need may have to sell the project at a very low price, because the market perceives the expected liquidity need to be low. Thus, in some cases, investors with high $\lambda$ 's choose portfolio investments in order to distinguish themselves from investors with low $\lambda$ 's and avoid the low period-1 prices. 
Proposition 3 shows that the only investment patterns that exist in a symmetric equilibrium are represented by Case 1 - a pooling equilibrium, in which all investors invest in direct investments - and Case 3 - a separating equilibrium, in which $\lambda_{H}$ investors invest in portfolio investments and $\lambda_{L}$ investors invest in direct investments. Case 3 is the case where portfolio investments are reversed more often and are more volatile than direct investments. This case is consistent with the casual observation that FDI investors are often large and stable multinational companies with low expected liquidity needs, whereas portfolio investors are, on average, more vulnerable to liquidity shocks. Case 1 is a case where the two types of investment have the same amount of reversals. In equilibrium, there is no case where direct investments are reversed more often than portfolio investments. This is because $\lambda_{L}$ investors always invest in direct investments, as they care less about the price they will get in period 1 , and prefer to stick with the more efficient investment.

As Proposition 3 shows, the level of $\lambda_{H}$ affects the set of possible equilibria. When $\lambda_{H}$ is higher than $\lambda_{H}^{* *}$, the difference between $\lambda_{L}$ and $\lambda_{H}$ is so large that investors with high expected liquidity needs $\left(\lambda_{H}\right.$ investors) never invest in direct investments. In this case, $\lambda_{H}$ investors prefer to invest in a less efficient investment in order not to be perceived as low- $\lambda$ investors and get a low price when they need to sell in period 1.

When $\lambda_{H}$ is between $\lambda_{H}^{*}$ and $\lambda_{H}^{* *}$, the difference between $\lambda_{L}$ and $\lambda_{H}$ is smaller. As a result, we have an equilibrium, in which $\lambda_{H}$ investors invest in direct investments. However, there is also another equilibrium, in which they invest in portfolio investments. The reason for the multiplicity of equilibria is the existence of externalities among $\lambda_{H}$ investors. $\mathrm{A} \lambda_{H}$ investor benefits from having other investors of her type investing in the same type of investment. This is because, then, when she tries to sell the project, the price will not be that low since the market knows that the sale is very likely to be driven by a liquidity shock. As a result, when all $\lambda_{H}$ investors invest in portfolio investments, an individual $\lambda_{H}$ investor would like to do the same thing in order to avoid the low price when she needs to sell (given that she needs to sell quite often). Similarly, when all $\lambda_{H}$ investors invest in direct investments, an individual $\lambda_{H}$ investor would like to invest in a portfolio investment as well.

When $\lambda_{H}$ is lower than $\lambda_{H}^{*}, \lambda_{H}$ investors always invest in direct investments. Here, the difference between $\lambda_{L}$ and $\lambda_{H}$ is small, and the dominant factor that determines the behavior of $\lambda_{H}$ investors is the greater efficiency associated with direct investments. 
Thus, Proposition 3 predicts that economies with large differences between the expected liquidity needs of different investors are more likely to exhibit separating equilibria with large differences in volatility between direct investments and portfolio investments. The existence of multiple equilibria for a certain range of the parameters implies that we may have jumps from an equilibrium with a lot of direct investments to an equilibrium with much less direct investments. This may explain why some countries have more direct investments than others, and why some periods of time are characterized by more direct investments than others.

Table 2 presents a numerical example that is based again on the case of a uniform distribution. The table shows the possible equilibria for different values of $\lambda_{H}$, and demonstrates the results of Proposition 3.

\begin{tabular}{|c|c|c|}
\hline$\lambda_{L}, \lambda_{H}$ & \multicolumn{2}{|c|}{ Possible Equilibria } \\
\hline & Case 1 & Case 3 \\
\hline$\lambda_{L}=0, \lambda_{H}=1$ & & + \\
\hline$\lambda_{L}=0.1, \lambda_{H}=0.9$ & & + \\
\hline$\lambda_{L}=0.2, \lambda_{H}=0.8$ & & + \\
\hline$\lambda_{L}=0.3, \lambda_{H}=0.7$ & + & + \\
\hline$\lambda_{L}=0.4, \lambda_{H}=0.6$ & + & \\
\hline$\lambda_{L}=0.5, \lambda_{H}=0.5$ & + & \\
\hline
\end{tabular}

Table 2: Numerical Example - Equilibrium Outcomes for different values of $\lambda_{H}$

At the end of the characterization of the equilibrium outcomes, we wish to discuss the possibility of existence of non-symmetric equilibria in the model, and show that our conclusions do not change when such equilibria are considered. The proof of Proposition 3 demonstrates that $\lambda_{L}$ investors will choose direct investments under all circumstances. Thus, a non-symmetric equilibrium can be only a case where some $\lambda_{H}$ investors choose direct investments, whereas others choose portfolio investments. When $\frac{1}{2}<\lambda_{H}<\lambda_{H}^{*}$, Case 1 is the only symmetric equilibrium, and we can show that the model does not have a non-symmetric equilibrium. This is because in this range of parameters, a $\lambda_{H}$ investor chooses a direct investment even when all other $\lambda_{H}$ investors choose portfolio investments, (this is the reason why Case 3 is not an equilibrium in this range). Thus, given that in this range, $\lambda_{H}$ investors choose direct investments even when portfolio investments 
are most beneficial, we can say that they will always choose to invest directly. Similarly, we can show that when $\lambda_{H}^{* *}<\lambda_{H}<1$, Case 3 is the only possible equilibrium of the model. When $\lambda_{H}^{*} \leq \lambda_{H} \leq \lambda_{H}^{* *}$, we have two symmetric equilibria - Case 1 and Case 3 - and one asymmetric equilibrium. In this asymmetric equilibrium, all $\lambda_{L}$ investors choose direct investments, whereas $\lambda_{H}$ investors split between direct investments and portfolio investments. This third equilibrium does not change our conclusions in any significant way, as it also features more reversals of portfolio investments than reversals of direct investments.

\subsection{Welfare Analysis}

As we noted in the last subsection, for some parameter values, our model has two possible equilibria: One equilibrium is referred to as Case 1 , in which both $\lambda_{H}$ and $\lambda_{L}$ investors choose direct investments, and the other one is referred to as Case 3, in which $\lambda_{H}$ investors choose portfolio investments and $\lambda_{L}$ investors choose direct investments. In this subsection, we study the differences in welfare across these two equilibria. As a starting point, we analyze foreign investors' welfare, given the current framework. Then, we use the result to study the implications for the welfare of residents of the host country, which is the main focus of our welfare analysis. We analyze only the range of parameters where the model has multiple equilibria. As we note at the end of the subsection, when the model has a unique equilibrium, this equilibrium also generates the highest possible welfare for the residents of the domestic country, and thus the analysis becomes straightforward.

The analysis of the ex ante welfare of the foreign investors in the current framework shows that when the two equilibria are possible, all investors gain a higher expected welfare when the pooling equilibrium (Case 1) occurs rather than when the separating equilibrium (Case 3) occurs. Thus, the equilibrium represented by Case 3 is Pareto-dominated by the one represented by Case 1 . We now demonstrate this point.

Under Case $3, \lambda_{H}$ investors choose portfolio investments and gain an expected payoff of $\frac{1}{2 A}$, whereas under Case 1, they choose direct investments and gain an expected payoff of $E V_{2, D i r e c t}\left(\lambda_{H}, \frac{1}{2}\right)$. This last expression is greater than $\frac{1}{2 A}$ by the first condition that makes Case 1 an equilibrium. Thus, when $\lambda_{H}$ investors choose portfolio investments in equilibrium, it is because of a coordination failure. Due to the efficiency of direct investments, their welfare is higher under Case 1, but they might end up in Case 3 because each $\lambda_{H}$ investor believes that others will invest in portfolio 
investments.

As for $\lambda_{L}$ investors, in both equilibria they choose direct investments. Under Case 3, their expected payoff is $E V_{2, \text { Direct }}\left(\lambda_{L}, \lambda_{L}\right)$, whereas under Case 1, their expected payoff is $E V_{2, \text { Direct }}\left(\lambda_{L}, \frac{1}{2}\right)$. Since $\varepsilon_{D}\left(\frac{1}{2}\right)>\varepsilon_{D}\left(\lambda_{L}\right)$, we know that $\lambda_{L}$ investors are better off in Case 1 . The reason is that under Case $1, \lambda_{H}$ investors also choose direct investments, and thus the price of direct investments in period 1 is higher.

We now turn to analyze the differences in welfare from the point of view of the residents of the host country. This analysis is important for a country that opens its borders to foreign capital flows, and is trying to assess what is the optimal composition of these flows. Again, we will focus on the range of parameters where there are two possible equilibria.

Up to this point, the residents of the host country did not have an explicit role in our model. A natural way to introduce them is to assume that they own the local projects initially, and sell them to foreign investors (suppose that the local residents do not have the ability to operate the projects). We assume that there is a continuum $[0,1]$ of local residents, each one holds an investment project in period 0. At this time, local residents sell the projects to the foreign investors. After the sales have taken place, the events in the model are exactly the same as we described before: In period 0 , foreign investors choose the form of investment, and in period 1 they make a decision on whether to sell their investments or not. Given this structure, the welfare analysis from the point of view of the local residents boils down to analyzing the price that they get for their projects in period 0 .

In period 0, there are two types of foreign investors buying the investment projects from the residents of the host country: $\lambda_{H}$ investors and $\lambda_{L}$ investors. Since the type of each investor is not observable (and given the fixed supply of investment projects), in a competitive equilibrium, the price of projects in period 0 will be determined by the lowest between the value that is incurred to $\lambda_{H}$ investors and the value that is incurred to $\lambda_{L}$ investors from holding the project. In our model, this is always the value that is incurred to $\lambda_{H}$ investors. Thus, $\lambda_{L}$ investors capture some of the rent due to their ability to maintain the project for a long time, and $\lambda_{H}$ investors do not capture any rent.

The price that local residents get for the projects in period 0 will then be $\frac{1}{2 A}$ when Case 3 is the realized equilibrium, and $E V_{2, \text { Direct }}\left(\lambda_{H}, \frac{1}{2}\right)$ when Case 1 is the realized equilibrium. As we showed above, when both equilibria are possible, the first expression is lower than the second one, meaning 
that domestic residents get higher prices when Case 1 is the realized equilibrium rather when Case 3 is the realized equilibrium. The implication is that if both Case 1 and Case 3 are possible as equilibrium outcomes, domestic residents are better off when Case 1 is realized. This suggests that the host country may benefit from encouraging more investments to be in the form of FDI. When only one of the two cases is a possible equilibrium, however, the price that domestic residents get in that equilibrium is higher than what they could have gotten under other alternative cases. Thus, there is a role for intervention only when the model has multiple equilibria.

\section{The Effect of Transparency}

The trade off between direct investments and portfolio investments in our model is based on asymmetric information between sellers and buyers, and between managers and owners. Greater transparency can reduce the degree of asymmetric information and alter the trade off between the two types of investment. In this section we modify the framework with heterogeneous investors developed in the last section, and analyze the effect of two measures of transparency. The first one, capital-market transparency, measures the degree of transparency between buyers and sellers. When this measure is higher, buyers are more informed about the reason, for which the investor is selling the project. The second one, corporate-governance transparency, measures the degree of transparency between managers and owners. When this measure is higher, owners, who do not act as managers, are more informed about the fundamentals of their projects.

This analysis will help us explain the empirical evidence, according to which the ratio between the volatility of foreign portfolio investments and the volatility of foreign direct investments is higher

in developing economies than in developed economies. Our hypothesis is that both measures of transparency are higher in developed economies than in developing economies. As we will show below, in some cases, more transparency will lead to less separation between $\lambda_{H}$ investors and $\lambda_{L}$ investors, and thus to lower differences in volatility between the two types of investment.

\subsection{Capital-Market Transparency}

Assume that with probability $\beta(0<\beta<1)$, the reason for an early sale in period 1 is known to all potential buyers. If this event happens, potential buyers know what triggers the liquidation of a 
project (that was held either as a direct investment or as a portfolio investment): A liquidity shock or a productivity shock. Assume also that sellers know whether the reason for a sale is revealed to buyers or not. Clearly, when $\beta$ is higher, the ex-ante level of transparency in the economy is higher.

The introduction of the parameter $\beta$ into the model does not change the payoffs from portfolio investments. Thus, for any value of $\beta$ between 0 and 1 , buyers know that a portfolio investment is always sold because of a liquidity shock. This is because the owner of a portfolio investment does not observe information on the realization of the productivity level. As a result, the expected payoff from a portfolio investment is independent of $\beta$ and is equal to $\frac{1}{2 A}$, as we showed before.

However, the analysis of direct investments is affected considerably by the introduction of $\beta$. Suppose that buyers know the reason for an early sale. If they know that the reason is a liquidity shock, the price they will be willing to pay in period 1 will be $\frac{1}{2 A}$, which is equal to the price they pay on a portfolio investment. If they know the reason is a productivity shock, no sale will take place. This is due to the classic 'lemons' problem: When a seller has superior information on the quality of the project, and the buyer knows that the sale is driven by this information, there will be no price that will satisfy both the buyer and the seller (see Akerlof, 1970). More technically, it is easy to verify that if the reason for the sale is known to the buyer, $\varepsilon_{D}$ (which is determined by (5) and (6)) will be equal to -1 , meaning that there are no sales in equilibrium. Then, denoting the probability of a liquidity shock for an individual investor as $\lambda_{i}$, and the probability that is perceived by the market as $\lambda_{m}$, we get that the expected payoff from a direct investment for this individual investor is $E V_{\beta, \text { Direct }}\left(\lambda_{i}, \lambda_{m}, \beta\right)$, where

$$
\begin{gathered}
E V_{\beta, \text { Direct }}\left(\lambda_{i}, \lambda_{m}, \beta\right)=\beta\left[\left(1-\lambda_{i}\right) \cdot \int_{-1}^{1} \frac{(1+\varepsilon)^{2}}{2 A} g(\varepsilon) d \varepsilon+\lambda_{i} \cdot \frac{1}{2 A}\right] \\
+(1-\beta)\left[\begin{array}{c}
\left(1-\lambda_{i}\right)\left[\int_{-1}^{\varepsilon_{D}\left(\lambda_{m}\right)} \frac{\left(1+\varepsilon_{D}\left(\lambda_{m}\right)\right)^{2}}{2 A} g(\varepsilon) d \varepsilon+\int_{\varepsilon_{D}\left(\lambda_{m}\right)}^{1} \frac{(1+\varepsilon)^{2}}{2 A} g(\varepsilon) d \varepsilon\right] \\
+\lambda_{i} \cdot \frac{\left(1+\underline{\varepsilon}_{D}\left(\lambda_{m}\right)\right)^{2}}{2 A}
\end{array}\right]
\end{gathered}
$$

As in the last section, there are four potential symmetric equilibria, denoted as cases 1-4. Proposition 4 characterizes the equilibrium outcomes that will hold under different parameter values. Again we make use of two threshold values of $\lambda_{H}$, which are defined below.

$$
\begin{aligned}
& \left.\lambda_{H}^{*}(\beta) \text { is given by (Here, } \lambda_{L}^{*}(\beta) \equiv\left(1-\lambda_{H}^{*}(\beta)\right)\right) \text { : } \\
& \qquad E V_{\beta, \text { Direct }}\left(\lambda_{H}^{*}(\beta), \lambda_{L}^{*}(\beta), \beta\right)=\frac{1}{2 A},
\end{aligned}
$$


and $\lambda_{H}^{* *}(\beta)$ is given by:

$$
E V_{\beta, \text { Direct }}\left(\lambda_{H}^{* *}(\beta), \frac{1}{2}, \beta\right)=\frac{1}{2 A} .
$$

Again, $\frac{1}{2}<\lambda_{H}^{*}(\beta)<\lambda_{H}^{* *}(\beta)<1$.

Proposition 4 For every $0<\beta<1$ :

When $\frac{1}{2}<\lambda_{H}<\lambda_{H}^{*}(\beta)$, only Case 1 is an equilibrium.

When $\lambda_{H}^{*}(\beta) \leq \lambda_{H} \leq \lambda_{H}^{* *}(\beta)$, both Case 1 and Case 3 are equilibria.

When $\lambda_{H}^{* *}(\beta)<\lambda_{H}<1$, only Case 3 is an equilibrium.

Both $\lambda_{H}^{*}(\beta)$ and $\lambda_{H}^{* *}(\beta)$ are increasing in $\beta$.

Proposition 4 shows that the characterization of equilibrium outcomes provided in Proposition 3 holds for every value of $\beta$ between 0 and 1. Thus, at low levels of $\lambda_{H}$, Case 1 is the only equilibrium, at high levels of $\lambda_{H}$, Case 3 is the only equilibrium, and at intermediate levels, both Case 1 and Case 3 are possible equilibria. The main point of Proposition 4 is that as $\beta$ increases, Case 3 becomes less likely to be an equilibrium and Case 1 becomes more likely to be an equilibrium. More technically: As $\beta$ increases, the range of $\lambda_{H}$, in which Case 3 is an equilibrium (between $\lambda_{H}^{*}(\beta)$ and 1 ), becomes smaller, and the range, in which Case 1 is an equilibrium (between $\frac{1}{2}$ and $\left.\lambda_{H}^{* *}(\beta)\right)$, becomes larger. Figure 2 illustrates the possible equilibrium outcomes as a function of $\lambda_{H}$ and $\beta$.

The implication of Proposition 4 is that in economies with more transparency between sellers and buyers, $\lambda_{H}$ investors and $\lambda_{L}$ investors are more likely to make the same investments rather than separate and invest in different types of investments, as they do in Case 3. As a result, in these economies, the difference between the volatility of direct investments and the volatility of portfolio investments is expected to be, on average, smaller. This may explain why developed economies are characterized by a lower ratio between the volatility of portfolio investments and the volatility of direct investments.

The intuition behind the result is strongly related to the basic trade off in our model. As we suggest in the paper, when investors make direct investments, they get more information on the fundamentals of the project, and can manage it more efficiently. However, this also has a disadvantage, since if they need to sell the project, this additional information will create a problem of asymmetric information between them and potential buyers, and will reduce the price they can 


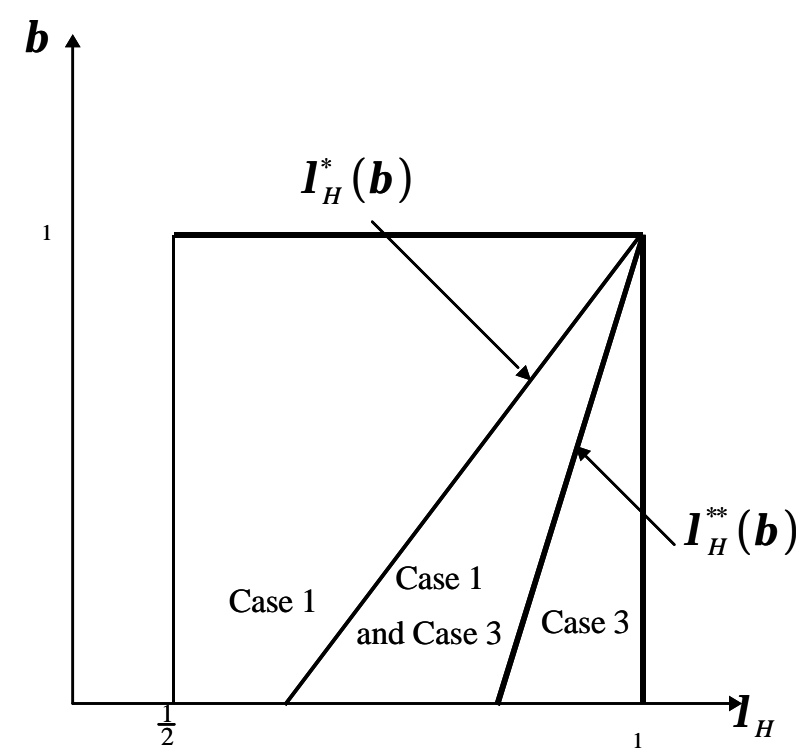

Figure 2: Possible Equilibria for Different Values of $\lambda_{H}$ and $\beta$

get. As a result, in equilibrium, investors that expect to sell more often, might make portfolio investments. When there is more transparency between buyers and sellers regarding the reason for an early sale, the problem of asymmetric information becomes smaller, and thus investors that expect to sell more often, have lower incentives to make portfolio investments.

\subsection{Corporate-Governance Transparency}

Assume that in case of a portfolio investment, the owner of the project observes $\varepsilon$ in period 1, with probability $\alpha(0<\alpha<1)$. If this happens, the owner of the project can act as a direct investor: She can instruct the manager to choose the optimal level of $k$, and she can decide to sell the project if the realization of $\varepsilon$ is below a certain threshold. Our interpretation is that a higher $\alpha$ represents a better flow of information between the manager and the owner when the two are not the same person. As a result, a higher $\alpha$ represents a higher level of ex ante transparency. For simplicity, in this subsection, we assume that $\beta=0$.

The introduction of the parameter $\alpha$ into the model does not change the analysis of direct investments. It only changes the analysis of portfolio investments. When owners of portfolio investments observe $\varepsilon$, they will be able to achieve the same management efficiency as direct investors. Thus, 
if they don't sell the project in period 1, their investment will yield an expected payoff of: $\frac{E(1+\varepsilon)^{2}}{2 A}$ (see (3)). Additionally, they also may decide to sell the project if the realization of $\varepsilon$ is below a certain level. We denote this threshold level of $\varepsilon$ as $\varepsilon_{P}$. Using the same principles as in (5) and (6), we derive the following equation that determines $\varepsilon_{P}$ as a function of $\alpha$ and $\lambda_{m}$ (the later is the probability of a liquidity shock that is perceived by the market):

$$
\frac{\left(1-\lambda_{m}\right) \alpha \int_{-1}^{\varepsilon_{P}\left(\alpha, \lambda_{m}\right)}(1+\varepsilon)^{2} g(\varepsilon) d \varepsilon+\lambda_{m}}{\left(1-\lambda_{m}\right) \alpha G\left(\underline{\varepsilon}_{P}\left(\alpha, \lambda_{m}\right)\right)+\lambda_{m}}=\left(1+\underline{\varepsilon}_{P}\left(\alpha, \lambda_{m}\right)\right)^{2} .
$$

This equation is slightly different from the one implied by (5) and (6), as it considers the fact that a portfolio investor observes $\varepsilon$ with probability $\alpha$. As we show in the Appendix, for every $\lambda_{m}$ and $\alpha$ between 0 and 1 , there is a unique solution for $\varepsilon_{P}$ between -1 and 0 . As we also show in the Appendix, the analysis of the equation reveals that $\varepsilon_{P}\left(\alpha, \lambda_{m}\right)$ is increasing in $\lambda_{m}$ and decreasing in $\alpha$. Thus, when the probability of a liquidity shock increases, there is, on average, a smaller problem of asymmetric information between sellers and buyers, and investors will sell their projects under a larger range of parameters. Similarly, when the probability of information being revealed to owners increases, there is, on average, a greater problem of asymmetric information, and investors will sell their projects under a smaller range of parameters. A direct result of the last property is that $\underline{\varepsilon}_{P}\left(\alpha, \lambda_{m}\right)>\underline{\varepsilon}_{D}\left(\lambda_{m}\right)$ for every $0<\alpha<1$.

Following (6), we know that the price of portfolio investments in period 1 will be: $\frac{\left(1+\varepsilon_{D}\left(\alpha, \lambda_{m}\right)\right)^{2}}{2 A}$. Then, the ex ante expected payoff from a portfolio investment for a $\lambda_{i}$ investor will be:

$$
\left(1-\lambda_{i}\right)\left[(1-\alpha) \cdot \frac{1}{2 A}+\alpha\left(\begin{array}{c}
\int_{-1}^{\varepsilon_{P}\left(\alpha, \lambda_{m}\right)} \frac{\left(1+\underline{\varepsilon}_{P}\left(\alpha, \lambda_{m}\right)\right)^{2}}{2 A} g(\varepsilon) d \varepsilon \\
+\int_{\underline{\varepsilon}_{P}\left(\alpha, \lambda_{m}\right)}^{1} \frac{(1+\varepsilon)^{2}}{2 A} g(\varepsilon) d \varepsilon
\end{array}\right)\right]+\lambda_{i} \cdot \frac{\left(1+\underline{\varepsilon}_{P}\left(\alpha, \lambda_{m}\right)\right)^{2}}{2 A} .
$$

When $0<\alpha<1$, the basic trade off between direct investments and portfolio investments is similar to the trade off in Section 5. On average, direct investments still provide more information to owners. This enables owners to achieve more management efficiency, but also reduces the price they can get when they sell their investments in period 1. As $\alpha$ increases, the differences between the expected payoffs from the two types of investment become smaller.

We now provide a partial characterization of equilibrium outcomes as a function of $\alpha$ and $\lambda_{H}$. Proposition 5 characterizes the range of parameters, for which Case 3 is an equilibrium. This range is also illustrated in Figure 3. 


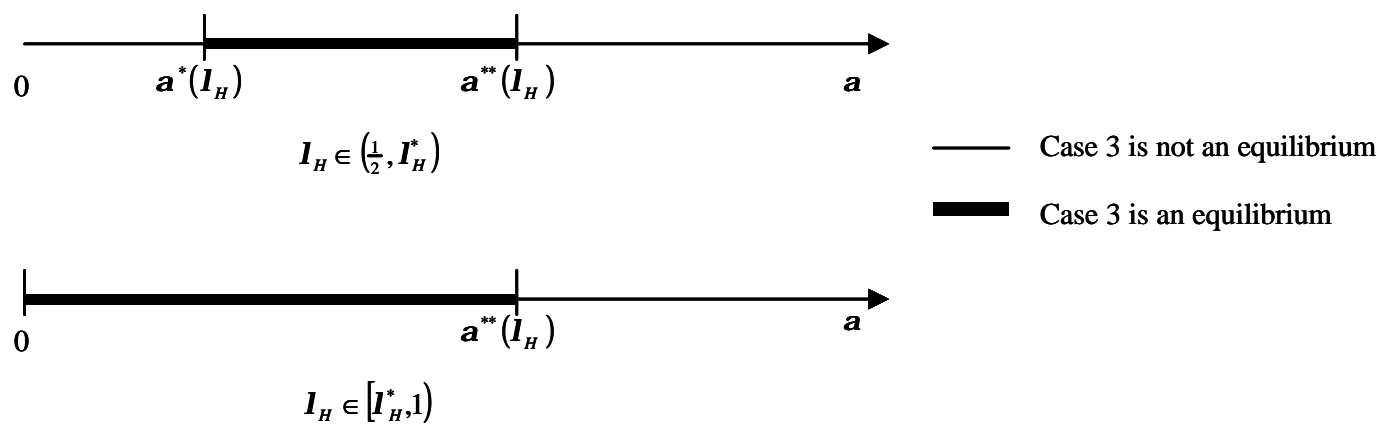

Figure 3: Realization of Case 3 as an Equilibrium

Proposition 5 For every $\lambda_{H}$, Case 3 is an equilibrium if and only if $\alpha \in\left[\alpha^{*}\left(\lambda_{H}\right), \alpha^{* *}\left(\lambda_{H}\right)\right]$. Here $\forall \lambda_{H} \in\left[\lambda_{H}^{*}, 1\right), \alpha^{*}\left(\lambda_{H}\right)=0$, and $\alpha^{* *}\left(\lambda_{H}\right) \in(0,1) ; \forall \lambda_{H} \in\left(\frac{1}{2}, \lambda_{H}^{*}\right), \alpha^{*}\left(\lambda_{H}\right) \in(0,1)$, and $\alpha^{* *}\left(\lambda_{H}\right) \in(0,1) . \lambda_{H}^{*}$ is defined by (11).

As the proposition shows, when $\alpha$ increases from an intermediate level to a high level, Case 3 ceases to be an equilibrium. The reason is that as $\alpha$ becomes high, the difference in efficiency between direct investments and portfolio investments becomes small. At the same time, if $\lambda_{H}$ investors invest in portfolio investments, period-1 prices of these investments will be high, and $\lambda_{L}$ investors will prefer to invest in portfolio investments themselves. As a result, when $\alpha$ is high, there cannot be an equilibrium, in which $\lambda_{H}$ investors make portfolio investments and $\lambda_{L}$ investors make direct investments. The implication of this result is that countries with high levels of $\alpha$ are less likely to be in an equilibrium, in which there is a full separation between $\lambda_{H}$ investors and $\lambda_{L}$ investors and the difference in volatility between the two types of investment is large.

The proposition also shows that for some range of $\lambda_{H}$ (between $\frac{1}{2}$ and $\lambda_{H}^{*}$ ), an increase in $\alpha$ from a low level to an intermediate level will generate the opposite result. In this range, as $\alpha$ increases, Case 3 becomes a possible equilibrium, since $\lambda_{H}$ investors have a higher incentive to make portfolio investments. Since in this range, $\alpha$ is still relatively small, $\lambda_{L}$ investors still prefer to make the direct investments.

To sum up, the proposition shows that for all values of $\lambda_{H}$, an increase in $\alpha$ from an intermediate level to a high level will eliminate Case 3 as a possible equilibrium. However, in a partial range of $\lambda_{H}$, an increase in $\alpha$ from a low level to an intermediate level will make Case 3 a possible equilibrium. Thus, the proposition provides partial support to the hypothesis that countries with 
higher levels of $\alpha$ are characterized by smaller differences in volatility between direct investments and portfolio investments. The proposition does suggest, however, that countries with intermediate levels of $\alpha$ are more likely to have Case 3 as an equilibrium than countries with high levels of $\alpha$.

As for the other potential symmetric equilibria: We can easily show that for every $\alpha$ between 0 and 1, Case 2 and Case 4 do not satisfy equilibrium conditions. In the general set-up, we could not characterize the values of $\alpha$, for which Case 1 is an equilibrium. In order to shed more light on this point, we ran a simulation for a uniform distribution of $\varepsilon$. Table 3 shows the possible symmetric equilibria for different values of $\alpha$ and $\lambda_{H}$, when $\varepsilon$ is uniformly distributed.

\begin{tabular}{||c||c|c|c|c|c||}
\hline \hline$\alpha \backslash \lambda_{H}$ & 0.6 & 0.7 & 0.8 & 0.9 & 1 \\
\hline \hline 0 & Case 1 & Case 1, Case 3 & Case 3 & Case 3 & Case 3 \\
\hline 0.1 & Case 1 & Case 1, Case 3 & Case 3 & Case 3 & Case 3 \\
\hline 0.2 & Case 1 & Case 1, Case 3 & Case 3 & Case 3 & Case 3 \\
\hline 0.3 & Case 1, Case 3 & Case 1, Case 3 & Case 3 & Case 3 & Case 3 \\
\hline 0.4 & Case 1, Case 3 & Case 1, Case 3 & Case 3 & Case 3 & Case 3 \\
\hline 0.5 & Case 1, Case 3 & Case 1, Case 3 & Case 3 & Case 3 & - \\
\hline 0.6 & Case 1, Case 3 & Case 1 & - & - & - \\
\hline 0.7 & Case 1 & Case 1 & - & - & - \\
\hline 0.8 & Case 1 & Case 1 & - & - & - \\
\hline 0.9 & Case 1 & Case 1 & - & - & - \\
\hline \hline
\end{tabular}

Table 3: Numerical Example - Symmetric Equilibria for Different Values of $\alpha$ and $\lambda_{H}$

As Table 3 shows, under a uniform distribution, $\alpha$ does not seem to have an effect on the possibility of Case 1 being an equilibrium. Only the level of $\lambda_{H}$ determines whether Case 1 will be an equilibrium or not. Thus, the only effect of $\alpha$ on investment patterns in equilibrium is achieved through its effect on the possibility of observing Case 3 as an equilibrium, which was stated in Proposition 5. Interestingly, the table shows that for some parameters, the model will not have any symmetric equilibria. We can show, that when this happens, the model will have one asymmetric equilibrium, in which $\lambda_{H}$ investors will choose portfolio investments, whereas $\lambda_{L}$ investors will split between direct investments and portfolio investments. Clearly, this case exhibits smaller differences in volatility between direct investments and portfolio investments than Case 3. 


\section{Concluding Remarks}

The model we developed in this paper describes an information-based trade off between direct investments and portfolio investments. According to the model, direct investors will be more informed about the fundamentals of their projects. This information will enable them to manage their projects more efficiently. However, it will also create an asymmetric-information problem in case they need to sell their projects prematurely, and will reduce the price they can get in that case. As a result, for some parameter values, investors, who know they are more likely to get a liquidity shock that forces them to sell early, will choose to make portfolio investments, whereas investors, who know they are less likely to get a liquidity shock, will choose to make direct investments.

This result can explain the empirical finding, according to which foreign portfolio investments are more volatile and exhibit much more reversals than foreign direct investments. Moreover, the model shows that transparency - both capital-market transparency and corporate-governance transparency - sometimes reduces the difference between the volatility of direct investments and

the volatility of portfolio investments. This result is consistent with the empirical finding that the ratio of FDI's volatility to other long-term flows' volatility is smaller in developing countries than in developed countries.

In the rest of this section, we highlight six additional implications of our model that seem to us as promising directions for future research.

One, the information-based trade off between direct investments and portfolio investments has implications for the expected yields on each type of investment. Thus, in case of a liquidity shock, direct investors get a very low return on their investment. Investors will be willing to bear that risk and make direct investments only if they are compensated in the form of a higher expected yield. In order to address this issue in an appropriate way, our model should be adjusted to include risk averse agents. As for empirical evidence, we are not aware of any empirical study that looked at the differences between the expected yield on direct investments and the expected yield on portfolio investments. We think our framework suggests an interesting testable prediction on this point.

Two, in a recent empirical study, Sorensen and Yosha (2002) find that greater portfolio holdings across countries are associated with more risk sharing, whereas greater FDI holdings across countries are not associated with more risk sharing. In our framework, the main risk that is associated with foreign direct investments is the risk of a liquidity shock, following which the investment has to 
be sold at a low price. Since the liquidity shock has the same effect on all the direct investments that are held by the same investor, investors cannot diversify this risk by holding more direct investments. Thus, our framework can explain why greater FDI holdings are not associated with more risk sharing. As for portfolio investments, our framework suggests that liquidity shocks have a smaller effect on the returns from portfolio investments, and that these returns are affected mainly by the technology shock that is specific to the investment. Thus, our framework suggests that greater portfolio holdings across countries may be associated with more risk sharing. We believe that a thorough examination of these issues is an interesting direction for future research.

Three, our model can be extended to include debt flows. As is well known in the theory of corporate finance, the price of debt is less sensitive to problems of asymmetric information. Thus, in our framework, the return on debt is expected to be less sensitive to liquidity shocks, and thus debt is expected to attract investors with high expected liquidity needs. Thus, our framework can also explain the high volatility of international debt flows.

Four, in Section 6, we developed the implications of transparency for cross-sectional differences between volatility of FDI and volatility of portfolio investments. An interesting extension is to analyze the implications of transparency for time-series differences between the volatilities of the two forms of investment. Thus, in times of crisis, transparency may be lower, and thus differences in volatility between FDI and portfolio investments may be greater. This is consistent with casual empirical observations.

Five, in our model, portfolio investments occur sometimes as a result of a coordination failure among investors with high expected liquidity needs. When this happens, the host country can be better-off if investors invest in direct investments. This point may have interesting policy implications: The government can eliminate the bad equilibrium by creating better conditions for direct investments, and thus gain a higher welfare. As our analysis suggests, these better conditions can be in the form of greater transparency, but also in other forms.

Six, a direct testable implication of our model is that FDI investments will be held by investors with low expected liquidity needs. This seems consistent with the casual observation that deeppocket multinational companies, who are less exposed to liquidity shocks, hold a large amount of FDI. A thorough examination of this point is an interesting topic for future research. 


\section{Appendix}

\section{Characterization of $\varepsilon_{D}(\lambda)$}

In order to find $\varepsilon_{D}(\lambda)$, we need to solve equations (5) and (6). Then, $\varepsilon_{D}(\lambda)$ is given by the following equation:

$$
\frac{\left(1+\varepsilon_{D}\right)^{2}}{2 A}=\frac{(1-\lambda) \int_{-1}^{\varepsilon_{D}} \frac{(1+\varepsilon)^{2}}{2 A} g(\varepsilon) d \varepsilon+\lambda \int_{-1}^{1} \frac{1+2 \varepsilon}{2 A} g(\varepsilon) d \varepsilon}{(1-\lambda) G\left(\varepsilon_{D}\right)+\lambda}
$$

which can be written as follows:

$$
F\left(\lambda, \varepsilon_{D}\right)=(1-\lambda)\left[\int_{-1}^{\varepsilon_{D}}\left[\left(1+\varepsilon_{D}\right)^{2}-(1+\varepsilon)^{2}\right] g(\varepsilon) d \varepsilon\right]+\lambda\left[\left(1+\varepsilon_{D}\right)^{2}-1\right]=0 .
$$

Analyzing this equation, we can see that when $0<\lambda<1$, then $-1<\varepsilon_{D}(\lambda)<0$. Moreover, as $\lambda$ approaches $0, \varepsilon_{D}(\lambda)$ approaches -1 , and as $\lambda$ approaches $1, \varepsilon_{D}(\lambda)$ approaches 0 .

Analyzing the derivatives of $F\left(\lambda, \varepsilon_{D}\right)$, we get:

$$
\frac{\partial F\left(\lambda, \varepsilon_{D}\right)}{\partial \lambda}=\left(1+\varepsilon_{D}\right)^{2}-1-\int_{-1}^{\varepsilon_{D}}\left[\left(1+\varepsilon_{D}\right)^{2}-(1+\varepsilon)^{2}\right] g(\varepsilon) d \varepsilon<0
$$

and

$$
\frac{\partial F\left(\lambda, \underline{\varepsilon}_{D}\right)}{\partial \varepsilon_{D}}=2\left(1+\varepsilon_{D}\right)\left[(1-\lambda) G\left(\varepsilon_{D}\right)+\lambda\right]>0
$$

Thus, for every $\lambda$ in the range $(0,1)$, we have a unique $\varepsilon_{D}(\lambda)$ in the range $(-1,0)$. Moreover, by the Implicit Function Theorem, we know that $\varepsilon_{D}^{\prime}(\lambda)>0$. QED.

\section{Proof of Proposition 1}

We write $\operatorname{Dif}(\lambda)$ as it is defined by (8) and by (9):

$$
\operatorname{Dif}(\lambda)=\lambda \frac{\left(1+\underline{\varepsilon}_{D}(\lambda)\right)^{2}}{2 A}+(1-\lambda)\left(\begin{array}{c}
\int_{-1}^{\varepsilon_{D}(\lambda)} \frac{\left(1+\varepsilon_{D}(\lambda)\right)^{2}}{2 A} g(\varepsilon) d \varepsilon \\
+\int_{\varepsilon_{D}(\lambda)}^{1} \frac{(1+\varepsilon)^{2}}{2 A} g(\varepsilon) d \varepsilon
\end{array}\right)-\frac{1}{2 A}
$$

We start by computing $\operatorname{Dif}(\lambda)$ as $\lambda$ approaches 0 . We already know that as $\lambda$ approaches 0 , $\varepsilon_{D}(\lambda)$ approaches -1 . Plugging this in the expression for Dif $(\lambda)$, we get that as $\lambda$ approaches 0 , Dif $(\lambda)$ approaches $\int_{-1}^{1} \frac{\varepsilon^{2}}{2 A} g(\varepsilon) d \varepsilon$. We can easily see that $\int_{-1}^{1} \frac{\varepsilon^{2}}{2 A} g(\varepsilon) d \varepsilon>0$.

We now compute Dif $(\lambda)$ as $\lambda$ approaches 1 . We already know that as $\lambda$ approaches $1, \varepsilon_{D}(\lambda)$ approaches 0 . Plugging this in the expression for Dif $(\lambda)$, we get that as $\lambda$ approaches 1 , Dif $(\lambda)$ approaches 0 . 
Finally, we analyze $\operatorname{Dif}(\lambda)$. We write $\operatorname{Dif}(\lambda)$ as follows:

$$
\operatorname{Dif}(\lambda)=(1-\lambda)\left(\begin{array}{c}
\int_{-1}^{\varepsilon_{D}(\lambda)} \frac{\left(1+\varepsilon_{D}(\lambda)\right)^{2}-(1+\varepsilon)^{2}}{2 A} g(\varepsilon) d \varepsilon \\
+\int_{-1}^{1} \frac{\varepsilon^{2}}{2 A} g(\varepsilon) d \varepsilon
\end{array}\right)-\lambda \frac{\left(1-\left(1+\varepsilon_{D}(\lambda)\right)^{2}\right)}{2 A} .
$$

Then, we compute $D i f^{\prime}(\lambda)$ :

$$
\begin{aligned}
D i f^{\prime}(\lambda)= & -\left(\begin{array}{c}
\int_{-1}^{\varepsilon_{D}(\lambda)} \frac{\left(1+\underline{\varepsilon}_{D}(\lambda)\right)^{2}-(1+\varepsilon)^{2}}{2 A} g(\varepsilon) d \varepsilon \\
+\int_{-1}^{1} \frac{\varepsilon^{2}}{2 A} g(\varepsilon) d \varepsilon
\end{array}\right)-\frac{\left(1-\left(1+\varepsilon_{D}(\lambda)\right)^{2}\right)}{2 A} \\
& +\underline{\varepsilon}_{D}^{\prime}(\lambda)\left(\frac{2 \lambda\left(1+\underline{\varepsilon}_{D}(\lambda)\right)}{2 A}+(1-\lambda) \int_{-1}^{\varepsilon_{D}(\lambda)} \frac{2\left(1+\underline{\varepsilon}_{D}(\lambda)\right)}{2 A} g(\varepsilon) d \varepsilon\right) .
\end{aligned}
$$

Thus, in order to show that $\operatorname{Dif}^{\prime}(\lambda)<0$, we need to show that

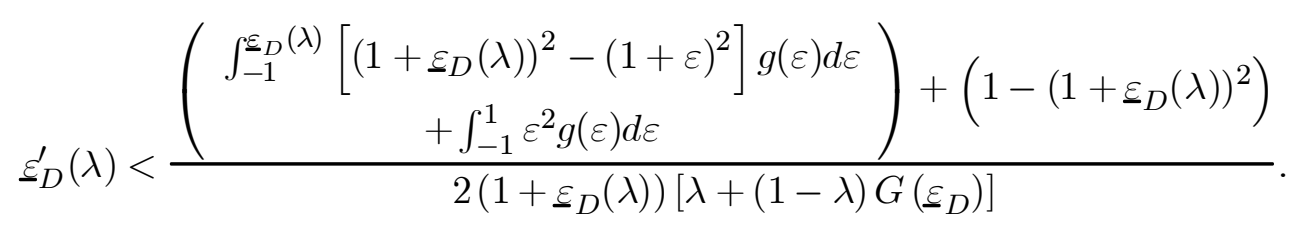

Using equations (5) and (6), we can see that:

$$
\underline{\varepsilon}_{D}^{\prime}(\lambda)=\frac{\left(1-\left(1+\underline{\varepsilon}_{D}(\lambda)\right)^{2}\right)+\int_{-1}^{\varepsilon_{D}}(\lambda)\left[\left(1+\underline{\varepsilon}_{D}(\lambda)\right)^{2}-(1+\varepsilon)^{2}\right] g(\varepsilon) d \varepsilon}{2\left(1+\underline{\varepsilon}_{D}(\lambda)\right)\left[\lambda+(1-\lambda) G\left(\underline{\varepsilon}_{D}(\lambda)\right)\right]} .
$$

Since $\int_{-1}^{1} \varepsilon^{2} g(\varepsilon) d \varepsilon>0$, we see that $\operatorname{Dif}^{\prime}(\lambda)<0$. QED.

\section{Proof of Proposition 3}

We start by showing that Case 2 and Case 4 cannot be equilibria.

One condition that is required for Case 2 to be an equilibrium is:

$$
\left(1-\lambda_{L}\right)\left[\int_{-1}^{\varepsilon_{D}\left(\frac{1}{2}\right)} \frac{\left(1+\varepsilon_{D}\left(\frac{1}{2}\right)\right)^{2}}{2 A} g(\varepsilon) d \varepsilon+\int_{\varepsilon_{D}\left(\frac{1}{2}\right)}^{1} \frac{(1+\varepsilon)^{2}}{2 A} g(\varepsilon) d \varepsilon\right]+\lambda_{L} \frac{\left(1+\varepsilon_{D}\left(\frac{1}{2}\right)\right)^{2}}{2 A} \leq \frac{1}{2 A} .
$$

However, from Proposition 1, we know that:

$$
\left(1-\frac{1}{2}\right)\left[\int_{-1}^{\varepsilon_{D}\left(\frac{1}{2}\right)} \frac{\left(1+\varepsilon_{D}\left(\frac{1}{2}\right)\right)^{2}}{2 A} g(\varepsilon) d \varepsilon+\int_{\varepsilon_{D}\left(\frac{1}{2}\right)}^{1} \frac{(1+\varepsilon)^{2}}{2 A} g(\varepsilon) d \varepsilon\right]+\frac{1}{2} \frac{\left(1+\varepsilon_{D}\left(\frac{1}{2}\right)\right)^{2}}{2 A}>\frac{1}{2 A} .
$$

Since $\lambda_{L}<\frac{1}{2}$, and $\int_{-1}^{\varepsilon_{D}\left(\frac{1}{2}\right)} \frac{\left(1+\underline{\varepsilon}_{D}\left(\frac{1}{2}\right)\right)^{2}}{2 A} g(\varepsilon) d \varepsilon+\int_{\varepsilon_{D}\left(\frac{1}{2}\right)}^{1} \frac{(1+\varepsilon)^{2}}{2 A} g(\varepsilon) d \varepsilon>\frac{\left(1+\varepsilon_{D}\left(\frac{1}{2}\right)\right)^{2}}{2 A}$, we get:

$$
\begin{aligned}
& \left(1-\lambda_{L}\right)\left[\int_{-1}^{\varepsilon_{D}\left(\frac{1}{2}\right)} \frac{\left(1+\varepsilon_{D}\left(\frac{1}{2}\right)\right)^{2}}{2 A} g(\varepsilon) d \varepsilon+\int_{\varepsilon_{D}\left(\frac{1}{2}\right)}^{1} \frac{(1+\varepsilon)^{2}}{2 A} g(\varepsilon) d \varepsilon\right]+\lambda_{L} \frac{\left(1+\underline{\varepsilon}_{D}\left(\frac{1}{2}\right)\right)^{2}}{2 A} \\
> & \left(1-\frac{1}{2}\right)\left[\int_{-1}^{\varepsilon_{D}\left(\frac{1}{2}\right)} \frac{\left(1+\varepsilon_{D}\left(\frac{1}{2}\right)\right)^{2}}{2 A} g(\varepsilon) d \varepsilon+\int_{\varepsilon_{D}\left(\frac{1}{2}\right)}^{1} \frac{(1+\varepsilon)^{2}}{2 A} g(\varepsilon) d \varepsilon\right]+\frac{1}{2} \frac{\left(1+\varepsilon_{D}\left(\frac{1}{2}\right)\right)^{2}}{2 A},
\end{aligned}
$$


and thus:

$$
\left(1-\lambda_{L}\right)\left[\int_{-1}^{\varepsilon_{D}\left(\frac{1}{2}\right)} \frac{\left(1+\varepsilon_{D}\left(\frac{1}{2}\right)\right)^{2}}{2 A} g(\varepsilon) d \varepsilon+\int_{\varepsilon_{D}\left(\frac{1}{2}\right)}^{1} \frac{(1+\varepsilon)^{2}}{2 A} g(\varepsilon) d \varepsilon\right]+\lambda_{L} \frac{\left(1+\varepsilon_{D}\left(\frac{1}{2}\right)\right)^{2}}{2 A}>\frac{1}{2 A} .
$$

As a result, Case 2 is never an equilibrium.

Using the same line of argument, we can show that

$$
\left(1-\lambda_{L}\right)\left[\int_{-1}^{\varepsilon_{D}\left(\lambda_{H}\right)} \frac{\left(1+\underline{\varepsilon}_{D}\left(\lambda_{H}\right)\right)^{2}}{2 A} g(\varepsilon) d \varepsilon+\int_{\underline{\varepsilon}_{D}\left(\lambda_{H}\right)}^{1} \frac{(1+\varepsilon)^{2}}{2 A} g(\varepsilon) d \varepsilon\right]+\lambda_{L} \frac{\left(1+\underline{\varepsilon}_{D}\left(\lambda_{H}\right)\right)^{2}}{2 A}>\frac{1}{2 A},
$$

and thus, Case 4 cannot be an equilibrium.

We now turn to analyze Case 1 and Case 3. Following the analysis above, we know that the second condition to establish Case 1 as an equilibrium (the condition that refers to $\lambda_{L}$ investors) always holds. Thus, Case 1 will be an equilibrium if and only if the first condition holds, that is, if and only if:

$$
\left(1-\lambda_{H}\right)\left[\int_{-1}^{\varepsilon_{D}\left(\frac{1}{2}\right)} \frac{\left(1+\varepsilon_{D}\left(\frac{1}{2}\right)\right)^{2}}{2 A} g(\varepsilon) d \varepsilon+\int_{\varepsilon_{D}\left(\frac{1}{2}\right)}^{1} \frac{(1+\varepsilon)^{2}}{2 A} g(\varepsilon) d \varepsilon\right]+\lambda_{H} \frac{\left(1+\varepsilon_{D}\left(\frac{1}{2}\right)\right)^{2}}{2 A} \geq \frac{1}{2 A},
$$

which can be simplified to the following condition:

$$
\left(1-\lambda_{H}\right)\left[\int_{-1}^{\varepsilon_{D}\left(\frac{1}{2}\right)}\left(1+\varepsilon_{D}\left(\frac{1}{2}\right)\right)^{2} g(\varepsilon) d \varepsilon+\int_{\varepsilon_{D}\left(\frac{1}{2}\right)}^{1}(1+\varepsilon)^{2} g(\varepsilon) d \varepsilon\right]+\lambda_{H}\left(1+\underline{\varepsilon}_{D}\left(\frac{1}{2}\right)\right)^{2} \geq 1 .
$$

Similarly, following Proposition 1, we know that the second condition to establish Case 3 as an equilibrium (the condition that refers to $\lambda_{L}$ investors) always holds. Thus, Case 3 will be an equilibrium if and only if the first condition holds, that is, if and only if:

$$
\left(1-\lambda_{H}\right)\left[\int_{-1}^{\varepsilon_{D}\left(\lambda_{L}\right)}\left(1+\underline{\varepsilon}_{D}\left(\lambda_{L}\right)\right)^{2} g(\varepsilon) d \varepsilon+\int_{\varepsilon_{D}\left(\lambda_{L}\right)}^{1}(1+\varepsilon)^{2} g(\varepsilon) d \varepsilon\right]+\lambda_{H}\left(1+\underline{\varepsilon}_{D}\left(\lambda_{L}\right)\right)^{2} \leq 1
$$

When we analyze (18) and (19), we can see that the LHS in (18) is higher than the LHS in (19). This is because $\lambda_{L}<\frac{1}{2}$, and because $\varepsilon_{D}(\lambda)$ is increasing in $\lambda$.

When $\lambda_{H}$ approaches 1 the LHS in (18) approaches $\left(1+\varepsilon_{D}\left(\frac{1}{2}\right)\right)^{2}$, which is lower than 1 . Then, in this case, the LHS in (19) is also lower than 1 . When $\lambda_{H}$ approaches $\frac{1}{2}$, the LHS in (19) approaches

$$
\frac{1}{2}\left[\int_{-1}^{\varepsilon_{D}\left(\frac{1}{2}\right)}\left(1+\varepsilon_{D}\left(\frac{1}{2}\right)\right)^{2} g(\varepsilon) d \varepsilon+\int_{\underline{\varepsilon}_{D}\left(\frac{1}{2}\right)}^{1}(1+\varepsilon)^{2} g(\varepsilon) d \varepsilon\right]+\frac{1}{2}\left(1+\varepsilon_{D}\left(\frac{1}{2}\right)\right)^{2},
$$


which, following Proposition 1, is higher than 1. Then, in this case, the LHS in (18) is also higher than 1.

The derivative of the LHS in (18) with respect to $\lambda_{H}$ is given by:

$$
\left(1+\varepsilon_{D}\left(\frac{1}{2}\right)\right)^{2}-\left[\int_{-1}^{\varepsilon_{D}\left(\frac{1}{2}\right)}\left(1+\varepsilon_{D}\left(\frac{1}{2}\right)\right)^{2} g(\varepsilon) d \varepsilon+\int_{\varepsilon_{D}\left(\frac{1}{2}\right)}^{1}(1+\varepsilon)^{2} g(\varepsilon) d \varepsilon\right]<0 .
$$

The derivative of the LHS in (19) with respect to $\lambda_{H}$ is given by: (recall that $\lambda_{L}=\left(1-\lambda_{H}\right)$ )

$$
\begin{aligned}
& \left(1+\varepsilon_{D}\left(\lambda_{L}\right)\right)^{2}-\left[\int_{-1}^{\varepsilon_{D}\left(\lambda_{L}\right)}\left(1+\varepsilon_{D}\left(\lambda_{L}\right)\right)^{2} g(\varepsilon) d \varepsilon+\int_{\varepsilon_{D}\left(\lambda_{L}\right)}^{1}(1+\varepsilon)^{2} g(\varepsilon) d \varepsilon\right] \\
& -2 \frac{\partial \varepsilon_{D}\left(1-\lambda_{H}\right)}{\partial\left(1-\lambda_{H}\right)} \cdot\left(1+\varepsilon_{D}\left(\lambda_{L}\right)\right) \cdot\left[\lambda_{H}+\left(1-\lambda_{H}\right) G\left(\varepsilon_{D}\left(\lambda_{L}\right)\right)\right]<0 .
\end{aligned}
$$

Thus, both the LHS in (18) and the LHS in (19) are higher than 1 when $\lambda_{H}$ approaches $\frac{1}{2}$, lower than 1 when $\lambda_{H}$ approaches 1 , and monotonically decreasing in $\lambda_{H}$. As a result, there exists a unique $\lambda_{H}^{*}$ between $\frac{1}{2}$ and 1 , at which the LHS in (19) equals 1 , and a unique $\lambda_{H}^{* *}$ between $\frac{1}{2}$ and 1, at which the LHS in (18) equals 1. Given that the LHS in (18) is higher than the LHS in (19), we know that $\lambda_{H}^{* *}>\lambda_{H}^{*}$.

Then, when $\frac{1}{2}<\lambda_{H}<\lambda_{H}^{*}$, only Case 1 is an equilibrium; when $\lambda_{H}^{*} \leq \lambda_{H} \leq \lambda_{H}^{* *}$, both Case 1 and Case 3 are equilibria; when $\lambda_{H}^{* *}<\lambda_{H}<1$, only Case 3 is an equilibrium. QED.

\section{Proof of Proposition 4}

The conditions required to establish each one of the four cases as an equilibrium are as follows:

\section{Case 1:}

$$
E V_{\beta, \text { Direct }}\left(\lambda_{H}, \frac{1}{2}, \beta\right) \geq \frac{1}{2 A}
$$

and

$$
E V_{\beta, \text { Direct }}\left(\lambda_{L}, \frac{1}{2}, \beta\right) \geq \frac{1}{2 A} .
$$

Case 2:

$$
E V_{\beta, \text { Direct }}\left(\lambda_{H}, \frac{1}{2}, \beta\right) \leq \frac{1}{2 A},
$$

and 


$$
E V_{\beta, \text { Direct }}\left(\lambda_{L}, \frac{1}{2}, \beta\right) \leq \frac{1}{2 A}
$$

\section{Case 3:}

$$
E V_{\beta, \text { Direct }}\left(\lambda_{H}, \lambda_{L}, \beta\right) \leq \frac{1}{2 A}
$$

and

$$
E V_{\beta, \text { Direct }}\left(\lambda_{L}, \lambda_{L}, \beta\right) \geq \frac{1}{2 A}
$$

\section{Case 4:}

$$
E V_{\beta, \text { Direct }}\left(\lambda_{H}, \lambda_{H}, \beta\right) \geq \frac{1}{2 A}
$$

and

$$
E V_{\beta, \text { Direct }}\left(\lambda_{L}, \lambda_{H}, \beta\right) \leq \frac{1}{2 A}
$$

Using the definition of $E V_{\beta, \text { Direct }}\left(\lambda_{i}, \lambda_{m}, \beta\right)$, the arguments in the proof of Proposition 3, and the fact that $\int_{-1}^{1}(1+\varepsilon)^{2} g(\varepsilon) d \varepsilon>1$, we get that Case 2 and Case 4 can never be equilibria, that Case 1 is an equilibrium if and only if

$$
\begin{gathered}
(1-\beta)\left[\begin{array}{c}
\left(1-\lambda_{H}\right)\left[\int_{-1}^{\varepsilon_{D}\left(\frac{1}{2}\right)}\left(1+\varepsilon_{D}\left(\frac{1}{2}\right)\right)^{2} g(\varepsilon) d \varepsilon+\int_{\underline{\varepsilon}_{D}\left(\frac{1}{2}\right)}^{1}(1+\varepsilon)^{2} g(\varepsilon) d \varepsilon\right] \\
+\lambda_{H} \cdot\left(1+\underline{\varepsilon}_{D}\left(\frac{1}{2}\right)\right)^{2}
\end{array}\right] \\
+\beta\left[\left(1-\lambda_{H}\right) \cdot \int_{-1}^{1}(1+\varepsilon)^{2} g(\varepsilon) d \varepsilon+\lambda_{H}\right] \geq 1
\end{gathered}
$$

and that Case 3 is an equilibrium if and only if

$$
\begin{gathered}
(1-\beta)\left[\begin{array}{c}
\left(1-\lambda_{H}\right)\left[\int_{-1}^{\varepsilon_{D}\left(\lambda_{L}\right)}\left(1+\underline{\varepsilon}_{D}\left(\lambda_{L}\right)\right)^{2} g(\varepsilon) d \varepsilon+\int_{\underline{\varepsilon}_{D}\left(\lambda_{L}\right)}^{1}(1+\varepsilon)^{2} g(\varepsilon) d \varepsilon\right] \\
+\lambda_{H}\left(1+\underline{\varepsilon}_{D}\left(\lambda_{L}\right)\right)^{2}
\end{array}\right] \\
+\beta\left[\left(1-\lambda_{H}\right) \cdot \int_{-1}^{1}(1+\varepsilon)^{2} g(\varepsilon) d \varepsilon+\lambda_{H}\right] \leq 1
\end{gathered}
$$

We know that $\left[\left(1-\lambda_{H}\right) \cdot \int_{-1}^{1}(1+\varepsilon)^{2} g(\varepsilon) d \varepsilon+\lambda_{H}\right]$ is decreasing in $\lambda_{H}$, higher than 1 when $\lambda_{H}$ approaches $\frac{1}{2}$, and approaches 1 when $\lambda_{H}$ approaches 1 . Then, using the arguments in the proof of Proposition 3, we get that both the LHS of (20) and the LHS of (21) are decreasing in $\lambda_{H}$, 
higher than 1 when $\lambda_{H}$ approaches $\frac{1}{2}$, and lower than 1 when $\lambda_{H}$ approaches 1 . We can also see that the LHS of (20) is higher than the LHS of (21).

As a result, for every $0<\beta<1$, there exists a unique $\lambda_{H}^{*}(\beta)$ between $\frac{1}{2}$ and 1 , at which the LHS in (21) equals 1 , and a unique $\lambda_{H}^{* *}(\beta)$ between $\frac{1}{2}$ and 1 , at which the LHS in (20) equals 1. Given that the LHS in (20) is higher than the LHS in (21), we know that $\lambda_{H}^{* *}(\beta)>\lambda_{H}^{*}(\beta)$. Then, when $\frac{1}{2}<\lambda_{H}<\lambda_{H}^{*}(\beta)$, only Case 1 is an equilibrium; when $\lambda_{H}^{*}(\beta) \leq \lambda_{H} \leq \lambda_{H}^{* *}(\beta)$, both Case 1 and Case 3 are equilibria; when $\lambda_{H}^{* *}(\beta)<\lambda_{H}<1$, only Case 3 is an equilibrium.

In order to show that $\lambda_{H}^{*}(\beta)$ and $\lambda_{H}^{* *}(\beta)$ are increasing in $\beta$, we need to show that the LHS in (21) and the LHS in (20) are increasing in $\beta$.

The derivative of the LHS in (21) with respect to $\beta$ is given by:

$$
\lambda_{H}\left[1-\left(1+\varepsilon_{D}\left(\lambda_{L}\right)\right)^{2}\right]-\left(1-\lambda_{H}\right)\left[\int_{-1}^{\varepsilon_{D}\left(\lambda_{L}\right)}\left(\left(1+\varepsilon_{D}\left(\lambda_{L}\right)\right)^{2}-(1+\varepsilon)^{2}\right) g(\varepsilon) d \varepsilon\right] .
$$

From (5) and (6), we know that:

$$
\lambda_{L}\left[1-\left(1+\varepsilon_{D}\left(\lambda_{L}\right)\right)^{2}\right]-\left(1-\lambda_{L}\right)\left[\int_{-1}^{\varepsilon_{D}\left(\lambda_{L}\right)}\left(\left(1+\varepsilon_{D}\left(\lambda_{L}\right)\right)^{2}-(1+\varepsilon)^{2}\right) g(\varepsilon) d \varepsilon\right]=0 .
$$

Then, since $\lambda_{H}>\lambda_{L}, 1-\left(1+\varepsilon_{D}\left(\lambda_{L}\right)\right)^{2}>0$ and $\int_{-1}^{\varepsilon_{D}\left(\lambda_{L}\right)}\left(\left(1+\varepsilon_{D}\left(\lambda_{L}\right)\right)^{2}-(1+\varepsilon)^{2}\right) g(\varepsilon) d \varepsilon<0$, we know that the expression in (22) is positive.

Applying similar arguments, we can also show that derivative of the LHS in (20) with respect to $\beta$ is positive. QED.

\section{Characterization of $\varepsilon_{P}\left(\alpha, \lambda_{m}\right)$}

Equation (16) can be written as:

$F_{P}\left(\lambda_{m}, \alpha, \underline{\varepsilon}_{P}\right)=\left(1-\lambda_{m}\right) \alpha \int_{-1}^{\varepsilon_{P}}\left[(1+\varepsilon)^{2}-\left(1+\varepsilon_{P}\right)^{2}\right] g(\varepsilon) d \varepsilon+\lambda_{m} \int_{-1}^{1}\left[1-\left(1+\varepsilon_{P}\right)^{2}\right] g(\varepsilon) d \varepsilon=0$.

The partial derivatives of $F_{P}\left(\lambda_{m}, \alpha, \varepsilon_{P}\right)$ with respect to $\lambda_{m}, \alpha$ and $\varepsilon_{P}$ are:

$$
\begin{gathered}
\frac{\partial F_{P}\left(\lambda_{m}, \alpha, \underline{\varepsilon}_{P}\right)}{\partial \lambda_{m}}=\int_{-1}^{1}\left[1-\left(1+\underline{\varepsilon}_{P}\right)^{2}\right] g(\varepsilon) d \varepsilon-\alpha \int_{-1}^{\varepsilon_{P}}\left[(1+\varepsilon)^{2}-\left(1+\underline{\varepsilon}_{P}\right)^{2}\right] g(\varepsilon) d \varepsilon>0, \\
\frac{\partial F_{P}\left(\lambda_{m}, \alpha, \underline{\varepsilon}_{P}\right)}{\partial \alpha}=\left(1-\lambda_{m}\right) \int_{-1}^{\varepsilon_{P}}\left[(1+\varepsilon)^{2}-\left(1+\underline{\varepsilon}_{P}\right)^{2}\right] g(\varepsilon) d \varepsilon<0,
\end{gathered}
$$


and

$$
\frac{\partial F_{P}\left(\lambda_{m}, \alpha, \varepsilon_{P}\right)}{\partial \underline{\varepsilon}_{P}}=-2\left(1+\underline{\varepsilon}_{P}\right)\left[\left(1-\lambda_{m}\right) \alpha G\left(\underline{\varepsilon}_{P}\right)+\lambda_{m}\right]<0 .
$$

Then, using the Implicit Function Theorem, we get that $\frac{\partial \varepsilon_{P}\left(\alpha, \lambda_{m}\right)}{\partial \alpha}<0$, and $\frac{\partial \varepsilon_{P}\left(\alpha, \lambda_{m}\right)}{\partial \lambda_{m}}>0$. Moreover, when $\lambda_{m}$ approaches $1, \varepsilon_{P}$ approaches 0 ; when $\lambda_{m}$ approaches $0, \varepsilon_{P}$ approaches -1 ; when $\alpha$ approaches $1, \varepsilon_{P}$ approaches $\varepsilon_{D}$; and when $\alpha$ approaches $0, \varepsilon_{P}$ approaches 0 . Thus, for every $\lambda_{m}$ and $\alpha$ between 0 and 1 , there is a unique solution for $\varepsilon_{P}$ between -1 and 1 . QED.

\section{Proof of Proposition 5}

The conditions for Case 3 to be an equilibrium are:

$$
\begin{aligned}
& \lambda_{H}\left(1+\underline{\varepsilon}_{D}\left(\lambda_{L}\right)\right)^{2}+\left(1-\lambda_{H}\right)\left(\begin{array}{c}
\int_{-1}^{\varepsilon_{D}\left(\lambda_{L}\right)}\left(1+\underline{\varepsilon}_{D}\left(\lambda_{L}\right)\right)^{2} g(\varepsilon) d \varepsilon \\
+\int_{\underline{\varepsilon}_{D}\left(\lambda_{L}\right)}^{1}(1+\varepsilon)^{2} g(\varepsilon) d \varepsilon
\end{array}\right) \\
& -\lambda_{H}\left(1+\varepsilon_{P}\left(\alpha, \lambda_{H}\right)\right)^{2}-\left(1-\lambda_{H}\right) \cdot\left[(1-\alpha)+\alpha\left(\begin{array}{c}
\int_{-1}^{\varepsilon_{P}\left(\alpha, \lambda_{H}\right)}\left(1+\varepsilon_{P}\left(\alpha, \lambda_{H}\right)\right)^{2} g(\varepsilon) d \varepsilon \\
+\int_{\varepsilon_{P}\left(\alpha, \lambda_{H}\right)}^{1}(1+\varepsilon)^{2} g(\varepsilon) d \varepsilon
\end{array}\right)\right] \\
& \leq 0 \text {, }
\end{aligned}
$$

and

$$
\begin{aligned}
& \lambda_{L}\left(1+\underline{\varepsilon}_{D}\left(\lambda_{L}\right)\right)^{2}+\left(1-\lambda_{L}\right)\left(\begin{array}{c}
\int_{-1}^{\varepsilon_{D}\left(\lambda_{L}\right)}\left(1+\underline{\varepsilon}_{D}\left(\lambda_{L}\right)\right)^{2} g(\varepsilon) d \varepsilon \\
+\int_{\underline{\varepsilon}_{D}\left(\lambda_{L}\right)}^{1}(1+\varepsilon)^{2} g(\varepsilon) d \varepsilon
\end{array}\right) \\
& -\lambda_{L}\left(1+\varepsilon_{P}\left(\alpha, \lambda_{H}\right)\right)^{2}-\left(1-\lambda_{L}\right) \cdot\left[(1-\alpha)+\alpha\left(\begin{array}{c}
\int_{-1}^{\varepsilon_{P}\left(\alpha, \lambda_{H}\right)}\left(1+\varepsilon_{P}\left(\alpha, \lambda_{H}\right)\right)^{2} g(\varepsilon) d \varepsilon \\
+\int_{\varepsilon_{P}\left(\alpha, \lambda_{H}\right)}^{1}(1+\varepsilon)^{2} g(\varepsilon) d \varepsilon
\end{array}\right)\right]
\end{aligned}
$$
$\geq 0$.

The derivative of the LHS in (24) with respect to $\alpha$ is:

$$
\begin{aligned}
& -\left(1-\lambda_{L}\right) \cdot\left[\begin{array}{c}
\int_{-1}^{\varepsilon_{P}\left(\alpha, \lambda_{H}\right)}\left(1+\varepsilon_{P}\left(\alpha, \lambda_{H}\right)\right)^{2} g(\varepsilon) d \varepsilon \\
+\int_{\varepsilon_{P}\left(\alpha, \lambda_{H}\right)}^{1}(1+\varepsilon)^{2} g(\varepsilon) d \varepsilon
\end{array}\right] \\
& -2 \frac{\partial \underline{\varepsilon}_{P}\left(\alpha, \lambda_{H}\right)}{\partial \alpha}\left(1+\underline{\varepsilon}_{P}\left(\alpha, \lambda_{H}\right)\right)\left[\lambda_{L}+\left(1-\lambda_{L}\right) \alpha G\left(\alpha, \varepsilon_{P}\left(\lambda_{H}\right)\right)\right],
\end{aligned}
$$

which is equal to 


$$
\begin{aligned}
& -\lambda_{H} \cdot\left[\begin{array}{c}
\int_{-1}^{\varepsilon_{P}\left(\alpha, \lambda_{H}\right)}\left(1+\varepsilon_{P}\left(\alpha, \lambda_{H}\right)\right)^{2} g(\varepsilon) d \varepsilon \\
+\int_{\varepsilon_{P}\left(\alpha, \lambda_{H}\right)}^{1}(1+\varepsilon)^{2} g(\varepsilon) d \varepsilon
\end{array}\right] \\
& +\frac{\left(1-\lambda_{H}\right)+\lambda_{H} \alpha G\left(\underline{\varepsilon}_{P}\left(\alpha, \lambda_{H}\right)\right)}{\left(1-\lambda_{H}\right) \alpha G\left(\alpha, \varepsilon_{P}\left(\lambda_{H}\right)\right)+\lambda_{H}} \cdot\left(1-\lambda_{H}\right) \int_{-1}^{\varepsilon_{P}\left(\alpha, \lambda_{H}\right)}\left[\left(1+\underline{\varepsilon}_{P}\left(\alpha, \lambda_{H}\right)\right)^{2}-(1+\varepsilon)^{2}\right] g(\varepsilon) d \varepsilon,
\end{aligned}
$$

which is lower than

$$
\begin{aligned}
& -\lambda_{H} \cdot\left[\begin{array}{c}
\int_{-1}^{\varepsilon_{P}\left(\alpha, \lambda_{H}\right)}\left(1+\varepsilon_{P}\left(\alpha, \lambda_{H}\right)\right)^{2} g(\varepsilon) d \varepsilon-1 \\
+\int_{\underline{\varepsilon}_{P}\left(\alpha, \lambda_{H}\right)}^{1}(1+\varepsilon)^{2} g(\varepsilon) d \varepsilon
\end{array}\right] \\
& +\lambda_{H} \int_{-1}^{\varepsilon_{P}\left(\alpha, \lambda_{H}\right)}\left[\left(1+\underline{\varepsilon}_{P}\left(\alpha, \lambda_{H}\right)\right)^{2}-(1+\varepsilon)^{2}\right] g(\varepsilon) d \varepsilon \\
= & \lambda_{H}\left(1-\int_{-1}^{1}(1+\varepsilon)^{2} g(\varepsilon) d \varepsilon\right)<0
\end{aligned}
$$

Thus, the derivative of the LHS in (24) with respect to $\alpha$ is negative. From Proposition 3 we know that the LHS in (24) is positive when $\alpha=0$, and since $\varepsilon_{P}\left(\alpha, \lambda_{H}\right)>\varepsilon_{D}\left(\lambda_{L}\right)$, we know it is negative when $\alpha=1$. As a result, for every $\lambda_{H}$, there is a unique $\alpha^{* *}\left(\lambda_{H}\right)$ in the range $(0,1)$, for which the LHS in (24) is equal to 0 . Condition (24) is satisfied if and only if $\alpha \leq \alpha^{* *}\left(\lambda_{H}\right)$.

Similarly, we can show that the derivative of the LHS in (23) with respect to $\alpha$ is negative. From Proposition 3 we know that the LHS in (23) is positive when $\alpha=0$ and $\lambda_{H}<\lambda_{H}^{*}$, and negative when $\lambda_{H}>\lambda_{H}^{*}$. Since $\varepsilon_{P}\left(\alpha, \lambda_{H}\right)>\varepsilon_{D}\left(\lambda_{L}\right)$, we know that the LHS in (23) is negative when $\alpha=1$. Thus, we can define a function $\alpha^{*}\left(\lambda_{H}\right): \forall \lambda_{H} \in\left[\lambda_{H}^{*}, 1\right), \alpha^{*}\left(\lambda_{H}\right)=0 ; \forall \lambda_{H} \in\left(\frac{1}{2}, \lambda_{H}^{*}\right)$, $\alpha^{*}\left(\lambda_{H}\right) \in(0,1)$, such that: Condition (23) is satisfied if and only if $\alpha \geq \alpha^{*}\left(\lambda_{H}\right)$.

Since the LHS in (24) is higher than the LHS in (23), we know that $\alpha^{*}\left(\lambda_{H}\right)<\alpha^{* *}\left(\lambda_{H}\right)$. As a result, Case 3 is an equilibrium if and only if $\alpha \in\left[\alpha^{*}\left(\lambda_{H}\right), \alpha^{* *}\left(\lambda_{H}\right)\right]$. QED.

\section{References}

[1] Admati, A. R. and P. Pfleiderer, 1988, "A Theory of Intraday Patterns: Volume and Price Variability," Review of Financial Studies, 1, 3-40.

[2] Admati, A. R. and P. Pfleiderer, 1991, "Sunshine Trading and Financial Market Equilibrium," Review of Financial Studies, 4, 443-481. 
[3] Akerlof, G. A., 1970, "The Market for 'Lemons': Quality Uncertainty and the Market Mechanism," Quarterly Journal of Economics, 89, 488-500.

[4] Albuquerque, R., 2002, "The Composition of International Capital Flows: Risk Sharing Through Foreign Direct Investment," Journal of International Economics, forthcoming.

[5] Bacchetta, P. and E. van Wincoop, 2000, "Capital Flows to Emerging Markets: Liberalization, Overshooting, and Volatility," in S. Edwards (ed.), Capital Flows and the Emerging Economies - Theory, Evidence, and Controversies, The University of Chicago Press, 61-98.

[6] Bayoumi, T. and G. Lipworth, 1997, "Japanese Foreign Direct Investment and Regional Trade," IMF Working Paper WP/97/103.

[7] Bolton, P. and E. L. von Thadden, 1998, "Blocks, Liquidity, and Corporate Control," Journal of Finance, 53, 1-25.

[8] Chuhan, P., G. Perez-Quiros and H. Popper, 1996, "Do Short-term Investment and Direct Investment Differ?," World Bank Policy Research Working Paper, 1669.

[9] Claessens, S., M. Dooley and A. Warner, 1995, "Portfolio Capital Flows: Hot or Cold?," The World Bank Economic Review, 9, 153-174.

[10] Diamond, D. W. and P. H. Dybvig, 1983, "Bank Runs, Deposit Insurance, and Liquidity," Journal of Political Economy, 91, 401-419.

[11] Foster, F. D. and S. Viswanathan, 1990, "A Theory of the Interday Variations in Volume, Variance, and Trading Costs in Securities Markets," Review of Financial Studies, 3, 593-624.

[12] Frankel, J. A. and A. K. Rose, 1996, "Currency Crashes in Emerging Markets: An Empirical Treatment," Journal of International Economics, 41, 351-366.

[13] Froot, K. A. and J. C. Stein, 1991, "Exchange Rates and Foreign Direct Investment: An Imperfect Capital Markets Approach," Quarterly Journal of Economics, 106, 1191-1217.

[14] Gordon, R. H. and A. L. Bovenberg, 1996, "Why Is Capital So Immobile Internationally? Possible Explanations and Implications for Capital Income Taxation," American Economic Review, 86, 1057-1075. 
[15] Hart, O., 2000, "Financial Contracting," Nancy L. Schwartz Lecture, Kellogg Graduate School of Management, Northwestern University.

[16] Hausmann, R. and E. Fernandez-Arias, 2000, "Foreign Direct Investment: Good Cholesterol?," Inter-American Development Bank Working Paper, 417.

[17] Kahn, C. and A. Winton, 1998, "Ownership Structure, Speculation, and Shareholder Intervention," Journal of Finance, 53, 99-129.

[18] Klein, M. W. and E. S. Rosengren, 1994, "The Real Excahnge Rate and Foreign Direct Investment in the United States," Journal of International Economics, 36, 373-389.

[19] Klein, M. W., J. Peek and E. S. Rosengren, 2002, "Troubled Banks, Impaired Foreign Direct Investment: The Role of Relative Access to Credit," American Economic Review, 92, 664-682.

[20] Lipsey, R. E., 1999, "The Role of Foreign Direct Investment in International Capital Flows," NBER Working Paper, 7094.

[21] Lipsey, R. E., 2001, "Foreign Direct Investors in Three Financial Crises," NBER Working Paper, 8084.

[22] Maug, E., 1998, "Large Shareholders as Monitors: Is There a trade off between Liquidity and Control?," Journal of Finance, 53, 65-98.

[23] Razin, A. and E. Sadka, 2003, "Gains from FDI Inflows with Incomplete Information," Economics Letters, 7, 71-77.

[24] Razin, A., E. Sadka and C-W Yuen, 1998, "A Pecking Order of Capital Inflows and International Tax Principles," Journal of International Economics, 44, 45-68.

[25] Sarno, L. and M. P. Taylor, 1999, "Hot Money, Accounting Labels and the Permanence of Capital Flows to Developing Countries: An Empirical Investigation," Journal of Developments Economics, 59, 337-364.

[26] Sorensen, B. E. and O. Yosha, 2002, "Home Bias and International Risk Sharing: Twin Puzzles Separated at Birth," work in progress, Tel Aviv University. 
[27] Stiglitz, J. E., 1975, "The Theory of 'Screening,' Education, and the Distribution of Income," American Economic Review, 65, 283-300.

[28] UNCTAD, 2001, "World Investment Report: Promoting Linkages, Overview," United Nations, New York.

[29] World Bank, 2002, "Global Development Finance," The World Bank, Washington D.C. 